\title{
Synthesis and coordination chemistry of cyclic seleno- and telluroureas
}

\author{
${ }^{1}$ Department of Chemistry, The University of Winnipeg, 515 Portage Avenue, Winnipeg, Manitoba R3B 2E9, Canada, E-mail: \\ j.ritch@uwinnipeg.ca
}

\begin{abstract}
:
Chalcogenated derivatives of N-heterocyclic carbene ligands have received increasing attention due to their diverse chemical reactivity and potential applications in fields such as medicine and materials chemistry. This chapter summarizes the synthetic methods for the preparation of cyclic heavy chalcogenoureas featuring heterocyclic cores and explores their diverse coordination chemistry with p- and d-block metals.
\end{abstract}

Keywords: chalcogenoureas, nitrogen heterocycles, coordination chemistry

DOI: $10.1515 /$ psr-2017-0128

\section{Introduction}

Selenium- and tellurium-containing analogues of urea and its $N$-substituted derivatives have received increasing attention in the last few decades. These heavy chalcogenoureas (HCUs) have been investigated in many areas from fundamental structural and coordination chemistry to applications in material science [1, 2], medicine [3], and biochemistry [4-6]. A large number of compounds fall into this distinction, and this chapter will focus in particular on cyclic seleno- and telluroureas, which are formally chalcogen derivatives of the popular $\mathrm{N}$-heterocyclic carbene (NHC) ligands and which feature flanking tertiary nitrogen centres. In the following sections, the preparation and physical properties of cyclic HCUs will be described, followed by a review of their coordination chemistry. Literature up to late 2017 is covered.

The chemistry of ureas and thioureas is of course very well developed in its own right, as are HCUs featuring less organo-substitution. There are many studies featuring acyclic HCUs such as $N, N$-dimethylselenourea, or those which are cyclic but featuring NH substituents (i. e. imidazolidine-2-selone). To provide a focused review, this contribution will only feature selenium and tellurium analogues featuring rings, and with full substitution at nitrogen. Many comprehensive reviews on related areas of chemistry are available, including main group carbene complexes (including non-chalcogens) [7, 8] and the redox chemistry of HCUs [3].

It should be noted that there are several names for this class of compound to be found in the literature, with no particular term being universally adopted. Popular examples include chalcone (selone or selenone, tellone or tellurone) and chalcogenourea (selenourea, tellurourea).

\section{Structural variety of cyclic HCUs}

Within this class of compounds, wherein the $\mathrm{C}=\mathrm{E}(\mathrm{E}=\mathrm{Se}, \mathrm{Te})$ carbon atom is within a ring, and each nitrogen atom contains one other organic substituent, there is considerable structural variation possible. Figure 1 illustrates the most common molecular architectures featuring the HCU functional group. The ring is usually five membered, though six- and seven-membered rings have been achieved as well. Flanking this ring are the two $N$-substituents which are usually the same group, though asymmetric variants are known. In particular, HCUs with more than one chalcogenourea group (Figure 2) often feature an alkyl or aryl spacer. The most commonly encountered HCU is 1,3-dimethylimidazole-2-selone (dmise), perhaps due to the ease of its preparation (see Section 3.3). 


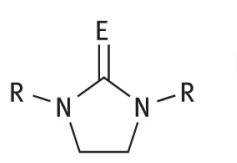<smiles>[R]N1CCCCN([R])C1=C</smiles><smiles>[R]C1=C([R])N([R])C(=C)N1[R]</smiles><smiles>[X]C1=C([X])N([R])C(=C)N1[R]</smiles>

$$
\mathrm{E}=\mathrm{Se}, \mathrm{Te}
$$

$\mathrm{R}=$ alkyl, aryl; $\mathrm{R}^{\prime}=\mathrm{H}, \mathrm{Me}, \mathrm{Cl} ; \mathrm{X}=\mathrm{O}, \mathrm{NR}, \mathrm{CR}_{2}$

Figure 1: Common HCU compounds with one $\mathrm{C}=\mathrm{E}$ functional group.<smiles>[R]n1ccn(Cn2ccn([R])c2=[Se])c1=[As]</smiles><smiles>[R]n1ccn(-c2cccc(-n3ccn([R])c3=[Se])c2)c1=[Se]</smiles><smiles>[R]N1C(=[Se])N([R])C2(NCCN2[R])C1=[Se]</smiles><smiles>[R]N1C(=[Se])N([R])C2C1N([R])C(=[Se])N2C</smiles><smiles>[R]n1c(=O)c2[nH]c(=[Se])n([R])c2n([R])c1=S</smiles>

Figure 2: $\mathrm{HCU}$ compounds with multiple $\mathrm{C}=\mathrm{E}$ functional groups.

\section{Synthesis of heavy chalcogenoureas}

Cyclic HCUs can be considered derivatives of NHC ligands, and most reported synthetic routes to these compounds begin by assembling the $N$-heterocyclic ring, i. e. an imidazolium or imidazolinium salt, prior to introduction of the chalcogen centre. The numerous routes to prepare carbene precursors have been reviewed thoroughly [9], and this section will focus on several synthetic routes to cyclic HCUs not including these prior steps.

\subsection{Direct chalcogenation}

If one has already prepared or purchased an NHC, then a direct reaction of the carbene with elemental chalcogen is quite facile, generally proceeding cleanly in any solvent compatible with the NHC, and without the need to elevate temperature (eq. (1)). Soon after reports of stable NHC ligands in the early 1990s [10, 11], telluroureas $[12,13]$ and then subsequently selenoureas [14] were prepared in this manner.

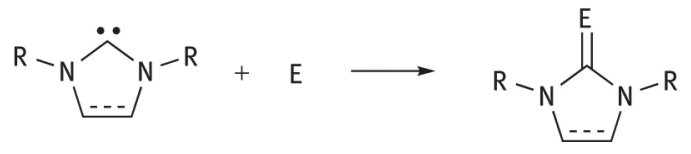

Biimidazolidines (carbene dimers) have been shown to react with elemental chalcogen (eq. (2)) to form a selenourea $(E=S e, R=P h)[15]$, and the first well-characterized example of a tellurourea $(E=T e, R=E t)[16]$. The selenium derivative formed in high yield in tetrahydrofuran (THF) solution at $0{ }^{\circ} \mathrm{C}$, while tellurourea formation required refluxing toluene. Interestingly, the latter method predates the advent of stable, "bottleable" carbenes [10] by nearly a decade. The tellurium derivative was reported to extrude tellurium and revert back to the biimidazolidine upon photolysis or thermolysis [16]. 


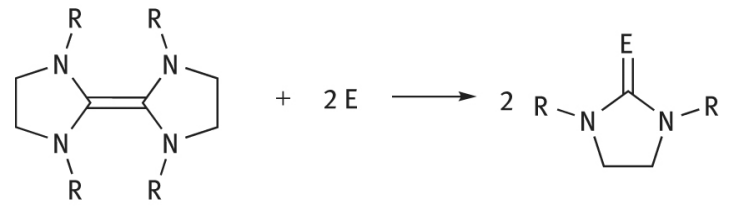

\subsection{Deprotonation-chalcogenation}

Most preparations of cyclic HCUs feature deprotonation of the imidazolium or imidazolinium salt with a base, and concomitant reaction with a chalcogen source (eq. (3). and Table 1). The base deprotonates the carbene precursor to yield an NHC in situ, which then reacts with the chalcogen source to form the desired HCU. These methods vary in the base and chalcogen source used, as well as other reaction conditions such as solvent and temperature. The two most commonly encountered protocols make use of powdered elemental chalcogen and either methanolic $\mathrm{K}_{2} \mathrm{CO}_{3}$ (entry 1 ) or $\mathrm{KO}^{t} \mathrm{Bu}$ in THF (entry 2) as the base/solvent system. The use of hindered alkoxide has the advantage of proceeding cleanly at room temperature, but requires anhydrous conditions. Methanolic potassium carbonate generally requires reflux for the reaction to progress, but anhydrous requirements are less strict and the reactions can sometimes be conducted under ambient conditions without a significant loss in product yield. This method dates back to 1970, when it was first used to generate a cyclic thiourea [17].

Table 1: Selected deprotonation-chalcogenation protocols for cyclic seleno- and telluroureas.

\begin{tabular}{|c|c|c|c|c|c|c|c|}
\hline Entry & Heterocycle & $\begin{array}{l}\text { Chalcogen } \\
\text { source }\end{array}$ & Base & Solvent & $\begin{array}{l}\text { Temperature, } \\
\text { time }\end{array}$ & $\begin{array}{l}\text { Product }(\% \\
\text { yield) }\end{array}$ & Reference \\
\hline 1 & $\begin{array}{l}\text { Mes }-N{ }_{N}-\text { Mes } \\
\begin{array}{l}E=S e: X=C l \\
E=T e, X=P F_{6}\end{array}\end{array}$ & Se or Te & $\mathrm{K}_{2} \mathrm{CO}_{3}$ & $\mathrm{MeOH}$ & $\begin{array}{l}24 \mathrm{~h}(\mathrm{Se}), 96 \mathrm{~h} \\
(\mathrm{Te})\end{array}$ & Mes $68-70 \%)$ & [42] \\
\hline 2 & 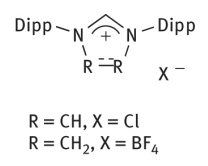 & Se & $\mathrm{KO}^{t} \mathrm{Bu}$ & THF & RT, overnight & $(81-86 \%)$ & {$[56]$} \\
\hline 3 & $\begin{array}{l}\mathrm{R}={ }_{\mathrm{B}}^{\mathrm{Bu}},{ }^{\mathrm{i} P r}{ }^{\mathrm{N}} \mathrm{Br}^{-} \\
\mathrm{F}^{-\mathrm{R}}\end{array}$ & $\begin{array}{l}\mathrm{Na}_{2} \mathrm{Se}_{2} \\
\text { or } \\
\mathrm{Na}_{2} \mathrm{Te}_{2}\end{array}$ & $\mathrm{KO}^{t} \mathrm{Bu}$ & THF & $\begin{array}{l}\text { 1) } \mathrm{Na}_{2} \mathrm{E}_{2}, 8 \mathrm{~h} \text {; } \\
\text { 2) } \mathrm{KO}^{\mathrm{t}} \mathrm{Bu}, 10 \mathrm{~h}\end{array}$ & \langle & [41] \\
\hline 4 & 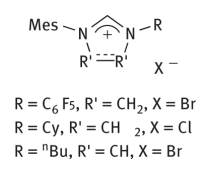 & Se & $\mathrm{NaN}\left(\mathrm{SiMe}_{3}\right)_{2}$ & $\mathrm{Et}_{2} \mathrm{O}$ & $\begin{array}{l}\text { 1) }-78^{\circ} \mathrm{C}, 30 \\
\text { min } \\
\text { 2) } \mathrm{RT} \text {, overnight }\end{array}$ & Mes- & [70] \\
\hline 5 & OTf & Se & $\mathrm{DBU}$ & $\mathrm{MeCN}$ & $\begin{array}{l}150^{\circ} \mathrm{C}(\mathrm{MW}), 1 \\
\mathrm{~h}\end{array}$ & (95\%) & [71] \\
\hline 6 & $\mathrm{Me}-{ }_{N} \widehat{+}_{N}-E t$ & Se & none & neat & $\begin{array}{l}75^{\circ} \mathrm{C} \text {, several } \\
\text { days }\end{array}$ & (91\%) & {$[72]$} \\
\hline
\end{tabular}




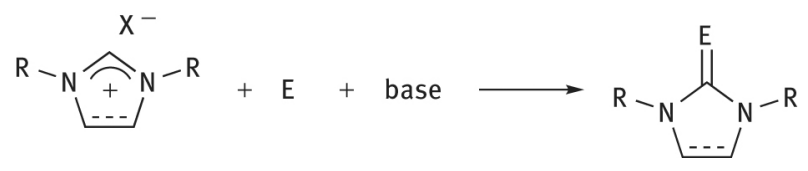

The use of $\mathrm{Na}_{2} \mathrm{E}_{2}$ salts has been reported as giving higher yields for benzimidazole derivatives (entry 3 ), versus the elemental chalcogens as powders. This requires the additional in situ preparation of the sodium dichalcogenide using a procedure such as sodium reduction of the chalcogen in THF in the presence of naphthalene as an electron donor catalyst [18]. Additionally, when used in an equimolar ratio with the carbenic species, the chalcogen is present in twofold excess. Nonetheless, this strategy has been reported to improve yields for some systems by up to $50 \%$ compared to using elemental chalcogen for some difficult transformations. $\mathrm{Na}_{2} \mathrm{Se}$ has been used as a stand-in for Se, eliminating the excess chalcogen, but this method has not been explored thoroughly and its scope is unknown.

Strong amide bases such as $\mathrm{NaN}\left(\mathrm{SiMe}_{3}\right)_{2}$ have been utilized (entry 4), though inert atmosphere and low temperature $\left(-78^{\circ} \mathrm{C}\right)$ conditions are required. The organic base DBU has been reported to effect high-yielding selenylation of a benzimidazolium triflate salt in acetonitrile under microwave irradiation (entry 5). Another interesting variation involves the anion of an imidazolium salt acting as the proton acceptor, without the need for an external base. The ionic liquid 1-ethyl-3-methylimidazolium acetate $\left(\mathrm{mp} 30^{\circ} \mathrm{C}\right)$ reacts with selenium in the absence of solvent to form the imidazole selone product (entry 6).

Most bidentate chalcogenourea ligands are prepared using the method from entry 1, using bis(imidazolium) bromide or iodide salts. Alkyl bridged bis(selone) ligands ( $n=1$ and 2 [19], 3 and 4 [20], 5 [21]) can be synthesized in this way (eq. (4)). In a study featuring the $n=2$ to 5 series, it was noted that the yield of the ethylene bridged $(n=2)$ bis(selone) ligand was noticeably lower (34\% versus $53-57 \%)$. A vinyl-substituted monoselone side product was also obtained from this reaction in $16 \%$ yield [6]. This suggests that a competing elimination pathway, such as that in eq. (5), is operating in this instance. Bis(benzimidazole chalcones) follow the general conditions of entry 3 (eq. (6)) [22].
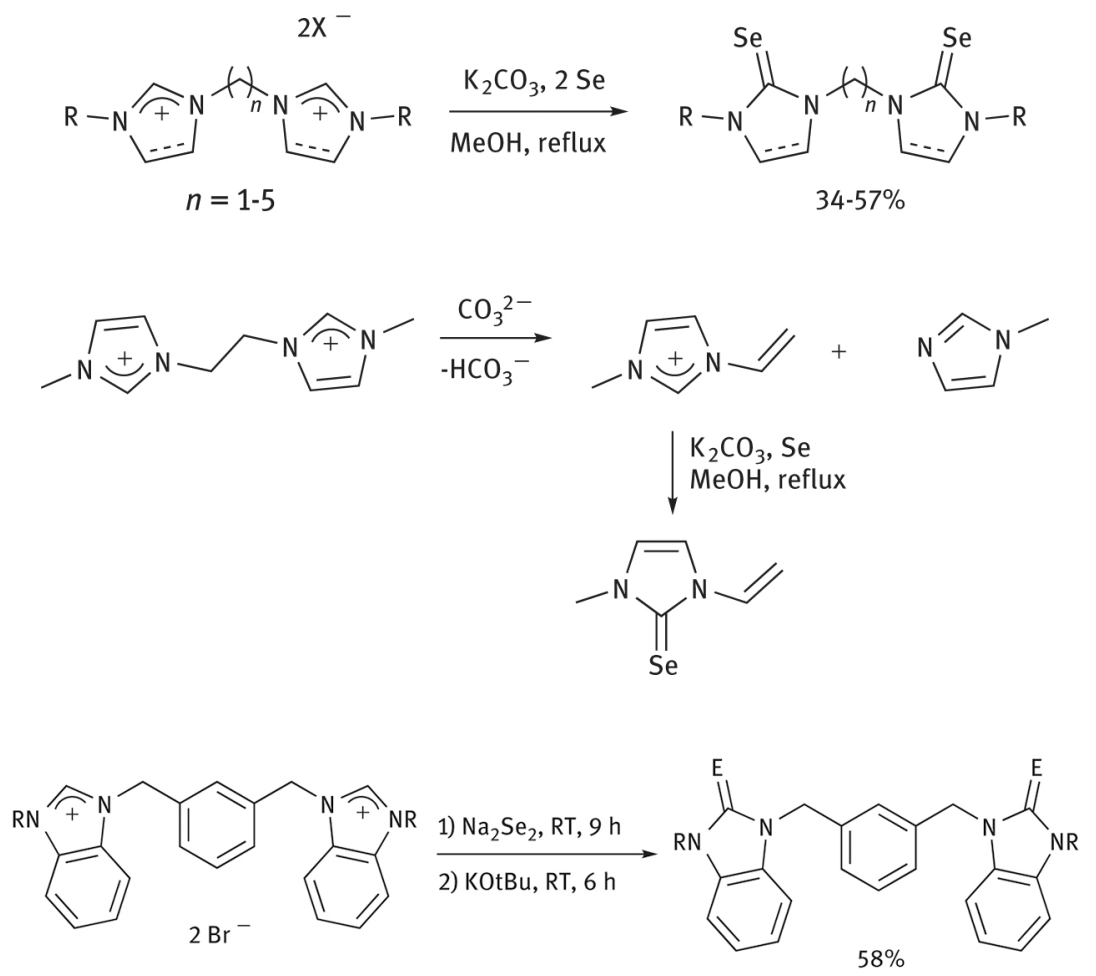

\subsection{One-pot reactions}

So-called one-pot syntheses combine the chalcogen addition step with one or more steps in the synthesis of imidazolium or imidazolinium precursors, in situ. Examples of this strategy include the use of $N, N^{\prime}$-disubstituted 
diaminoethanes and triethylorthoformate in a high-temperature sealed bomb reaction with selenium, to form selenoureas with an imidazoline backbone (eq. (7)). The tert-butyl substituted product was only obtained in $39 \%$, but the other derivatives afforded yields of $85-95 \%[6,23]$.

$$
\text { 年 }
$$

Other reports have combined the chalcogenation with alkylation of an imidazole or benzimidazole molecule to yield HCUs. For example, the popular HCU dmise was first reported in 1993, made by alkylating 1methylimidazole with methyl iodide in ethyl acetate, decanting off the solvent, then refluxing in methanolic $\mathrm{K}_{2} \mathrm{CO}_{3}$ in the presence of selenium (eq. (8)) [24]. Other electrophilic carbon sources can be used to install the second substituent, including benzyl halides [25, 26]; whether or not these procedures are 'one pot' depends on whether the imidazolium salt alkylation product is isolated or not, which varies from study to study.

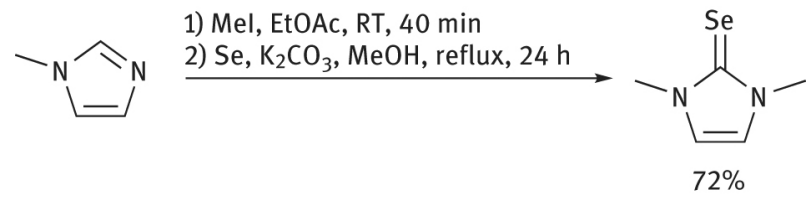

\subsection{Other methods}

A few other methods which do not fit into the previous categories have also been reported. 2-Selenoethersubstituted imidazoles have been observed to undergo thermal rearrangement to the cyclic selenourea isomer, via migration of the alkyl or benzyl group from selenium to nitrogen (eq. (9)). In one report, the transformation was monitored by nuclear magnetic resonance (NMR) spectroscopy $(\mathrm{R}=\mathrm{Me}, \mathrm{Bn}$; solvent not specified) and occurred between 40 and $50^{\circ} \mathrm{C}$ [26]. Another article describes the isomerization occurring in methanol solutions between 35 and $40^{\circ} \mathrm{C}$ for $\mathrm{R}=\mathrm{Me}, m$-oMeBn [27].

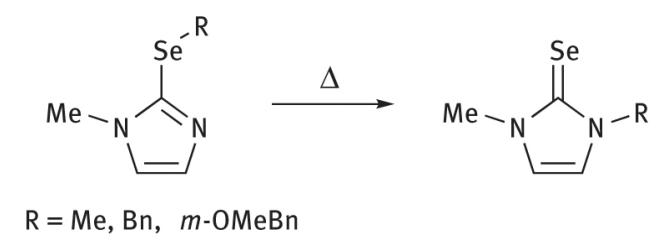

Diorganosubstituted acyclic selenoureas have been cyclized to yield oxamide-type heterocycles via reaction with oxalyl chloride and base (eq. (10)) [28]. This method was found to be more effective and operationally simpler than a previously reported method of transforming acyclic thioureas to selenoureas involving akylation at sulfur, followed by treatment with sodium hydrogen selenide (eq. (11)) [29]. A cyclic selenourea was also reported to form during thermal decomposition of a formal $\mathrm{NHC}^{-\mathrm{CSe}} \mathrm{e}_{2}$ adduct (eq. (12)), albeit with a low yield of $11 \%$. The conversion was increased to $21 \%$ in the presence of excess elemental selenium [30].

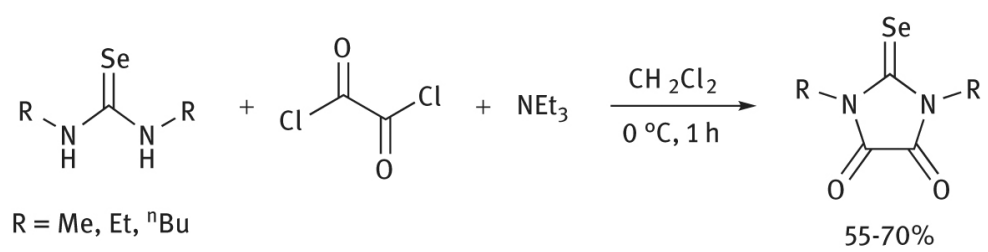




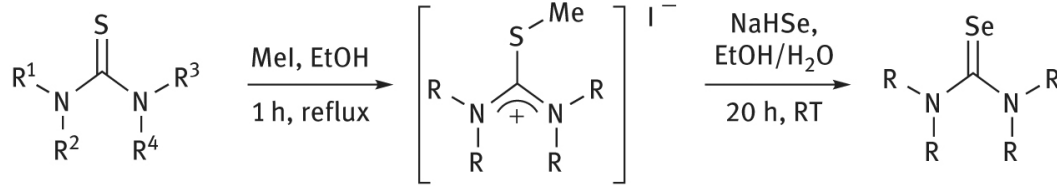

$$
\begin{aligned}
& \mathrm{R}=\mathrm{H}, \mathrm{Me}, \mathrm{Et}, \mathrm{Ph}
\end{aligned}
$$

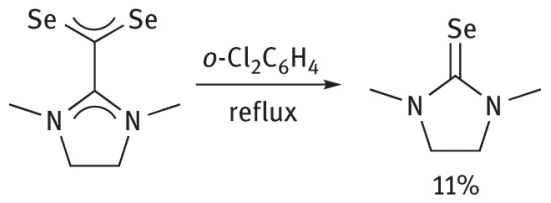

Five-membered selenohydantoin derivatives are accessible via the reaction of alkyl- or aryl-substituted isoselenocyanates with $\alpha$-amino acids (eq. (13)) [31]. This method does not require an added base, but conversion depends strongly on the substitution of the amino acid substrate. $\beta$-Amino acids did not give high conversion to six-membered heterocycles. For instance, $N$-methylanthranilic acid yielded only $25 \%$ of the desired product, while $\beta$-alanine yielded an acyclic disubstituted selenourea with no ring-closure product observed.
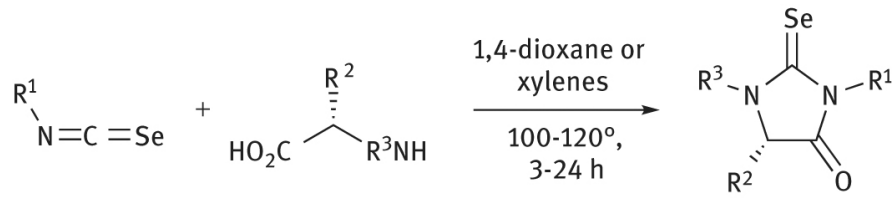

$26-99 \%$

\section{General properties of HCUs}

Cyclic selenoureas, unlike their NHC counterparts, are generally air- and moisture-stable crystalline solids which are stable to column chromatography and can be stored under ambient conditions. However, telluroureas are prone to detelluration and have been reported as being light and moisture sensitive, and slowly depositing tellurium mirrors when in solution [32]. Solubility in organic solvents is a function of substitution pattern; typically, selenoureas are more soluble than telluroureas, and those with more aliphatic groups are more soluble than those with more aromatic substituents.

The frontier molecular orbitals of dmise (M06-2X/6-31G(d,p)), a typical HCU compound, are illustrated in Figure 3. The highest occupied molecular orbital (HOMO) and HOMO-1 consist primarily of seleniumcentred p orbitals, and these, along with the aforementioned partial negative charge, highlight the ability of the chalcogen centre of HCUs to coordinate to metal centres (see Section 6). The HOMO-2 shows $\pi$-bonding character for the $C=$ Se fragment and the $C=C$ unit of the imidazole ring, while the LUMO orbital is $\pi$ antibonding with respect to $\mathrm{C}=$ Se and the imidazole N-C-N unit. A density functional theory (DFT) study (MPW1PW91/LANL2DZ(dp)/6-311G(d,p)) on benzimidazole chalcogenones revealed similar contributions of the $\mathrm{C}=\mathrm{E}$ fragment to the HOMO and LUMO of these compounds [32]. Natural bond orbital analysis revealed the chalcogen centres bear a partial negative charge (approximate averages of S: -0.25 ; Se: -0.20 ; Te: -0.15 ), while the directly bound carbon atom is positive (ca. +0.0 .13 to +0.30$)$. Wiberg bond indices for the chalcogenone functionality also revealed a decrease in double-bond character going from $S$ to Te. A DFT study on related 2imidazolones (B3LYP/LAV3P/6-31G(d,p)) attributes this trend to an increased contribution to the resonance hybrid by a zwitterionic form [33]. (Figure 4).
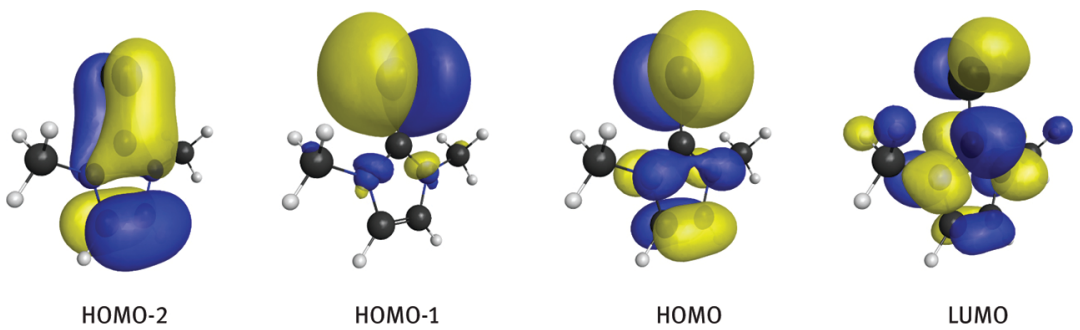

Figure 3: Frontier orbitals of dmise. 


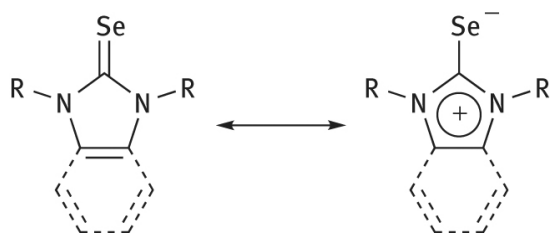

Figure 4: Resonance contributors to the electronic structure of HCUs.

Many cyclic HCUs have been characterized by single-crystal X-ray diffraction. These studies reveal several characteristic structural features. The $\mathrm{N}-\mathrm{C}(=\mathrm{E})-\mathrm{N}$ framework is planar, as expected for a functional group featuring lone pair delocalization. The average $\mathrm{C}=\mathrm{Se}$ and $\mathrm{C}=$ Te bond distances found in the Cambridge Structural Database represent contractions of ca. $5 \%$ and $2 \%$, respectively, compared to the sum of the covalent radius values (1.833(15) Å from 88 hits, 2.068(12) ̊̊ from 12 hits, respectively) [34]. This supports the presence of some multiple bond character between the carbon and chalcogen atoms. The average NCN bond angles of HCUs are found to be $106(2)^{\circ}$; large deviations from this average can be found with atypical ring sizes e. g. a sevenmembered ring $\left(118^{\circ}\right.$, Figure 5) [35].

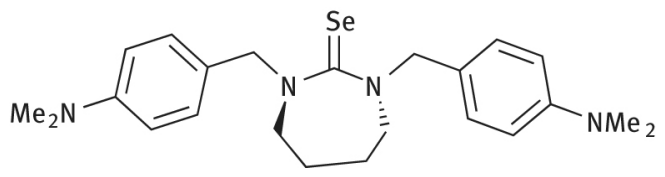

Figure 5: Structure of an HCU with a large NCN bond angle.

\section{$5 \quad{ }^{77} \mathrm{Se}$ and ${ }^{125} \mathrm{Te}$ NMR spectroscopic properties}

These compounds have been used as probes of the electronic properties of parent NHC ligands [36-38], as has been done for phosphinidenes [39]. In particular, ${ }^{77}$ Se NMR $(I=1 / 2,7.6 \%)$ resonances for various cyclic selenoureas have been associated with the $\pi$-accepting ability of the parent NHC ligand. The chemical shift values were found to be correlated to the energy gap of an $\mathrm{Se}(n) \rightarrow(\mathrm{C}=\mathrm{Se}) \pi^{*}$ transition, while no correlation between the $\sigma$-bonding energy (as determined by energy decomposition analysis) and chemical shift was found.

Though fewer in number, several cyclic telluroureas have been characterized by ${ }^{125} \mathrm{Te}$ NMR $(I=1 / 2,7.0 \%)$ spectroscopy (see Table 2 for a survey of relevant compounds). The range of chemical shifts for the species listed spans from $\delta-168$ to -4 and seems to reflect similar trends as has been observed for the Se-containing analogues. Those telluroureas expected to be more $\pi$-accepting, e. g. a chlorosubstituted imidazole-based HCU $(\delta-4$, entry 1$)$ and the imidazoline $(\delta-55.5$, entry 3$)$ are found at the higher frequency end of the range, while less $\pi$-accepting HCUs including imidazole-based derivatives are found at the lower frequency end ( $\delta-168$, entry $2 ; \delta-150$, entry 1$)$. However, the delineations are not all clear, as the similarly substituted TeIMes and TeIPr exhibit very disparate chemical shifts of $\delta-150$ (entry 1 ) and -52 (entry 3), respectively. The benzimidazole selenoureas in entries 4-6, which feature alkyl or benzyl substituents, resonate in the fairly narrow range $\delta-143$ to 126. Further study in this area would be warranted to examine if there is any correlation between bonding tendencies and the ${ }^{125} \mathrm{Te}$ chemical shift, as has been done for the selenium derivatives [36-38].

Table 2: Selected ${ }^{125} \mathrm{Te}$ NMR data for some cyclic telluroureas.

\begin{tabular}{|c|c|c|c|c|}
\hline Entry & Compound & $\delta\left({ }^{125} \mathrm{Te}\right)(\mathrm{ppm})$ & Solvent & Reference \\
\hline 1 & & $\begin{array}{l}\mathrm{R}=\mathrm{H}:-149.8 \\
\mathrm{R}=\mathrm{Cl}:-4.08\end{array}$ & THF- $\mathrm{d}_{8}$ & [13] \\
\hline 2 & & $\begin{array}{l}\mathrm{R}=\mathrm{Me}:-168.13 \\
\mathrm{R}={ }^{\mathrm{i}} \mathrm{Pr}:-167.82\end{array}$ & $\mathrm{C}_{6} \mathrm{D}_{6}$ & [73] \\
\hline
\end{tabular}


3<smiles>[R]n1[Y]:[Y](C)n([R])c1=[Te]</smiles>

$\mathrm{R}=$ Dipp, $\mathrm{X}=\mathrm{CH}$

$\mathrm{R}=$ Mes, $\mathrm{X}=\mathrm{CH}_{2}$

4<smiles>CCC(C)n1c(=O)n(CC(C)C)c2ccccc21</smiles>

5<smiles>[R]n1c(=[Te])n(Cc2ccccc2Br)c2ccccc21</smiles>

$$
\mathrm{R}={ }^{\mathrm{n}} \mathrm{Bu},{ }^{\mathrm{i}} \mathrm{Pr}
$$

6<smiles>CCC(C)n1c(=[Te])n(Cc2cccc(Cn3c(=[Te])n(C(C)(C)C)c4ccccc43)c2)c2ccccc21</smiles>

$\mathrm{R}=$ Dipp $, \mathrm{X}=\mathrm{CH}:-52.4 ; \quad \mathrm{CDCl}_{3}$

$\mathrm{R}=$ Mes, $\mathrm{X}=\mathrm{CH}_{2}:-55.5$

[74]

$-143$

$\mathrm{CDCl}_{3}$

[41]

$\mathrm{R}={ }^{\mathrm{n}} \mathrm{Bu}:-130$;

$\mathrm{CDCl}_{3}$

$\mathrm{R}={ }^{\mathrm{i}} \operatorname{Pr}:-126$

$\mathrm{CDCl}_{3}$

[22]

\section{Coordination chemistry}

A plethora of metal complexes have been prepared using cyclic HCUs. This section is categorized by block and group of the periodic table, and will focus on salient structural features of those complexes whose crystal structures have been determined. Exhaustive structural parameters and features such as co-crystallized solvent are omitted in favour of a general discussion of trends in aggregation type and coordination number. For multistep syntheses, yields (when available) are given are for the last step in the preparation.

\section{1 p-block (groups 13-16)}

Among the group 13 elements, thallium(I) complexes with two bis(selenoureas) exhibit two motifs (eq. (14)) [40]. Upon reaction with thallium(I)hexafluorophosphate in acetonitrile, a bridging coordination mode is adopted within the resulting coordination polymer. Treating the ligand with a thallium(I) diarylaurate salt in THF yields a chelated thallium(I) centre engaged in metal-metal bonding with the gold(I) centre. The bimetallic units are linked by $\mathrm{Tl} \cdots$ Se and $\mathrm{CH} \cdots$ Se interactions to afford coordination polymers. 


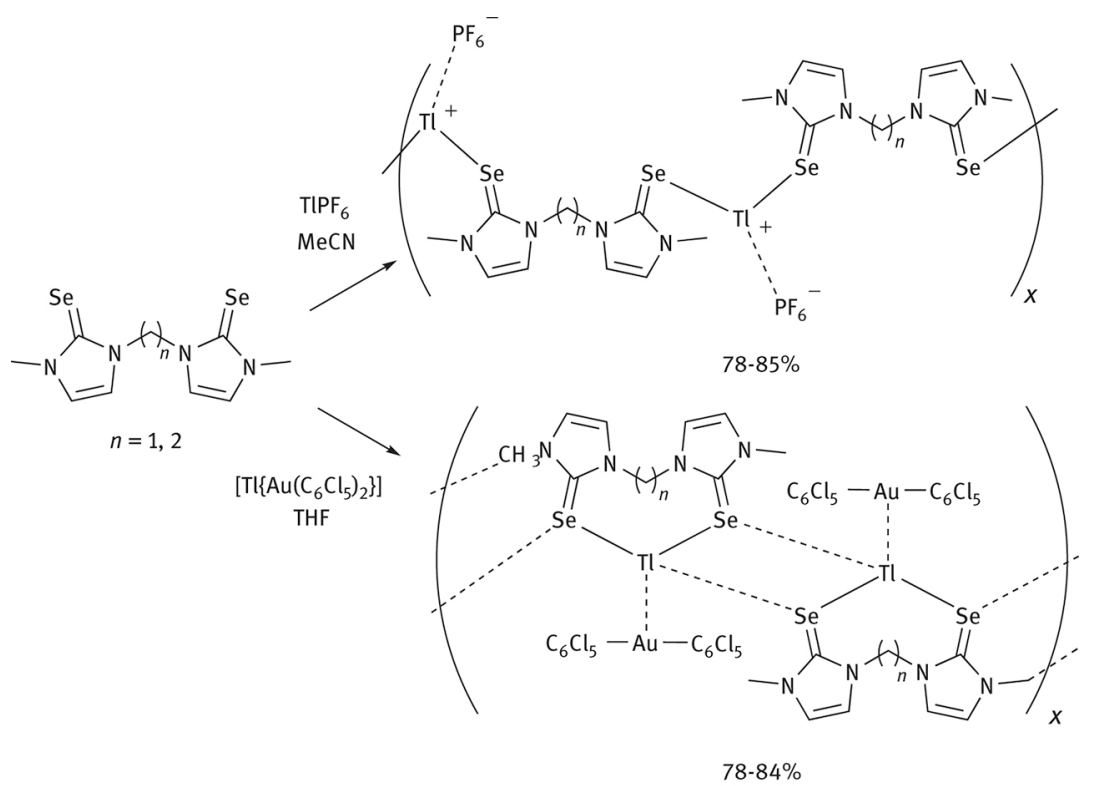

The heavier group 14 elements are represented by several tin complexes. Octahedral tin(IV) halide complexes of a benzimidazole HCU were prepared by reaction of hypervalent T-shaped halogen complexes with tin metal (eq. (15)) [41]. The two selenoureas are trans to each other in the coordination sphere. No germanium or lead complexes have been reported.

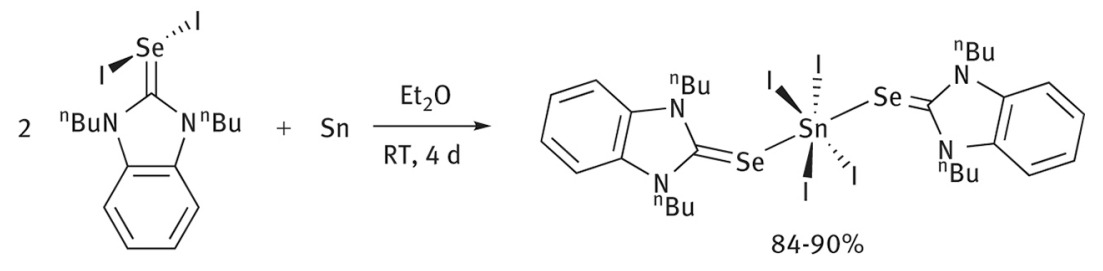

The reaction of this hypervalent selenourea derivative with bismuth(III) iodide yielded a tetrameric cluster featuring a double seco-cubane motif (eq. (16)). In another study, the use of bulkier aryl-substituted selenoureas afforded two different types of complexes, depending on the size of the pendent aromatic groups. For diisopropylphenyl substitution, monometallic $\left[\mathrm{LBiX}_{3}\right]$ complexes were obtained, while in the case of smaller mesityl groups, bimetallic complexes of type $\left[\left\{\mathrm{LBiX}_{2}\left(\mu_{2}-\mathrm{X}\right)\right\}_{2}\right]$ formed (eq. (17)) [42]. In both cases, bismuth $\cdots$ aryl interactions are observed. Analogous tellurourea complexes were synthesized but were not able to be studied by X-ray diffraction or NMR spectroscopy, due to very low solubility. A phosphorus adduct of a selenourea, via reaction with the phosphadiazonium salt [Mes*N $\equiv$ P]OTf, has been reported (eq. (18)) [43].
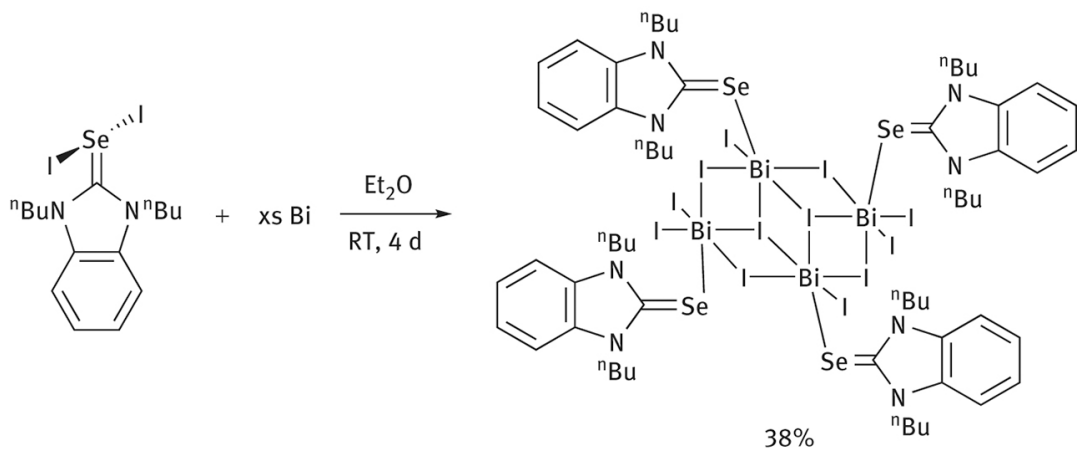

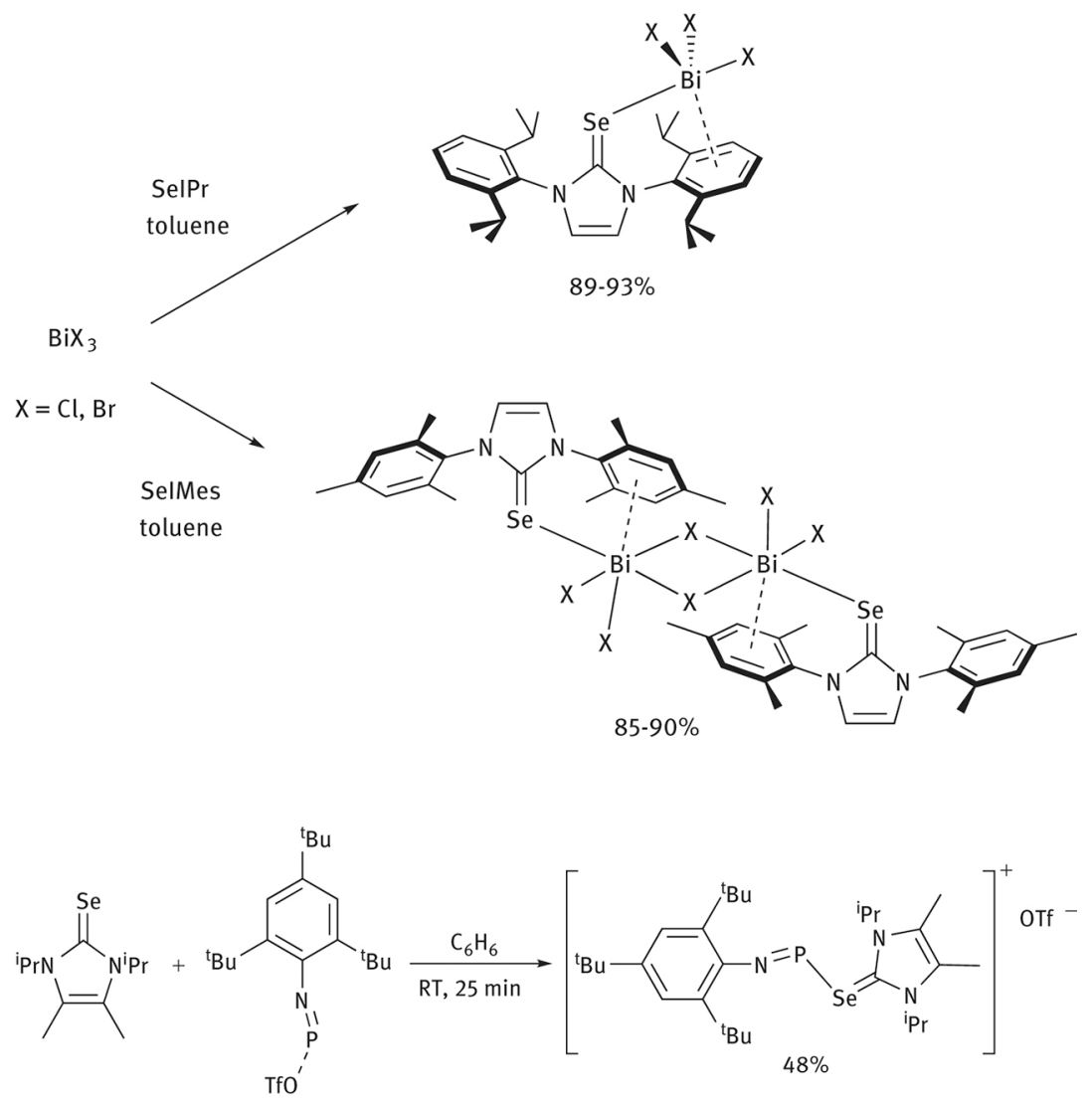

Complexes of the heavier group 16 elements with cyclic HCUs have been reported. The reaction of benzimidazole selenourea dihalides with a diaryl ditelluride resulted in the formation of HCU-stabilized T-shaped aryltellurenyl halides (eq. (19)). Halide abstraction with silver tetrafluoroborate in acetonitrile afforded the bent HCU-stabilized aryltellurenyl cation. When reacting various benzimidazole selone dihalides with elemental tellurium, a slow conversion to bis-adducts of $\mathrm{Te}^{\mathrm{IV}}$ tetrahalides was observed (eq. (20)) [41]. The two selone ligands are trans to each other in the coordination environment of tellurium. The reactions give moderate (50$60 \%$ ) conversion to product when conducted with excess powdered tellurium, and the yields do not improve when a 2:1 ratio of ligand:tellurium is utilized. In one instance $\left(\mathrm{R}={ }^{\mathrm{n}} \mathrm{Bu}, \mathrm{X}=\mathrm{Br}\right)$, a square-planar $\mathrm{Te} \mathrm{e}^{\mathrm{II}}$ complex was obtained as a minor by-product in $10 \%$ yield.

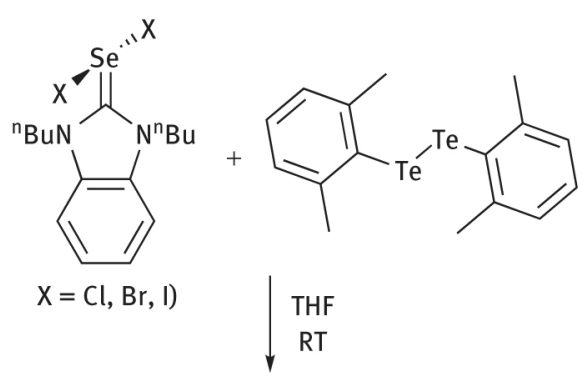

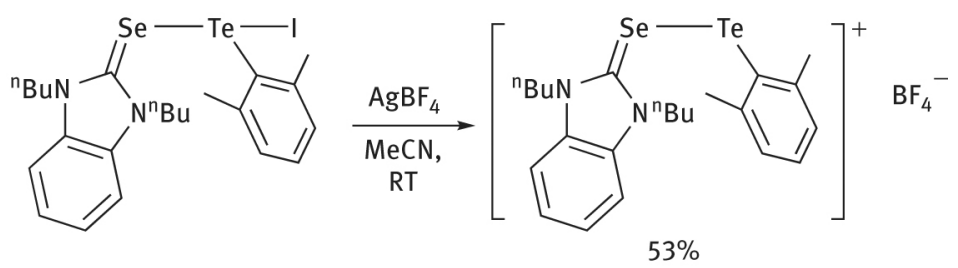




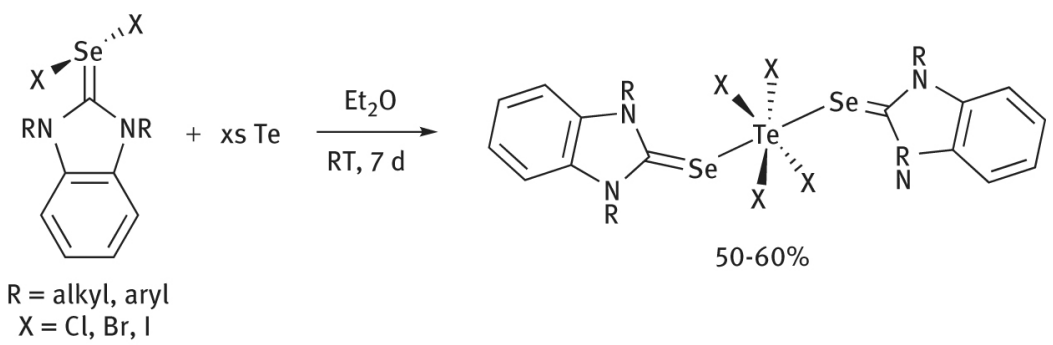

\subsection{Group 12}

The first crystal structure of a group 12 cyclic HCU complex was the simple bis(dmise) adduct of zinc(II) chloride (eq. (21)), reported in 2002 [44]. Recently, benzimidazole selone adducts of zinc(II) halides have been prepared (eq. (21)) [45]. Two other zinc complexes are known, both selenourea adducts of zinc(II) perchlorate (eq. (22)) [46]. The first is a tetracoordinate structure with a distorted tetrahedral geometry at zinc, while the second is an unusual bent two-coordinate motif (Se-Zn-Se bond angle of ca. $103^{\circ}$ ). Interestingly, the original ligands feature a free carboxylic acid, but under the reaction conditions these functional groups esterify.
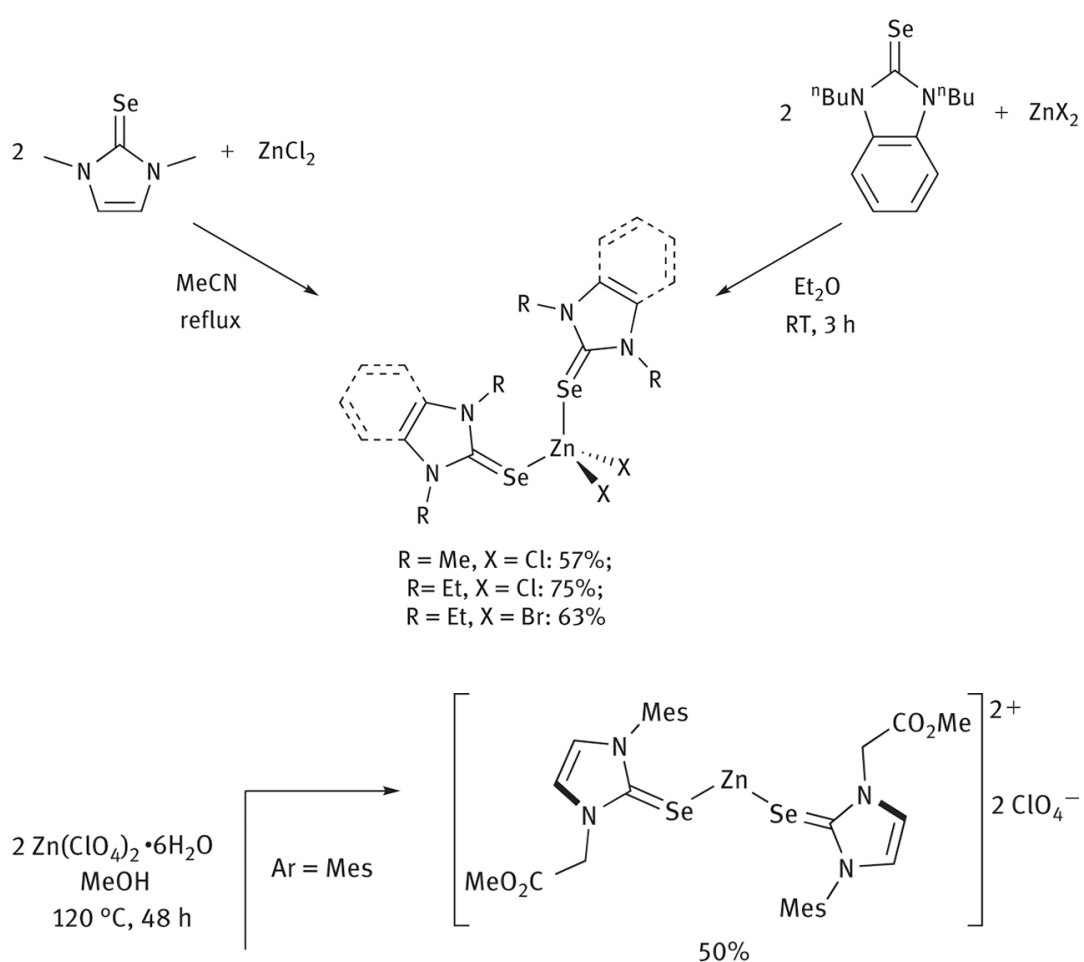<smiles>O=C(O)Cn1ccn([Al])c1=[Se]</smiles>
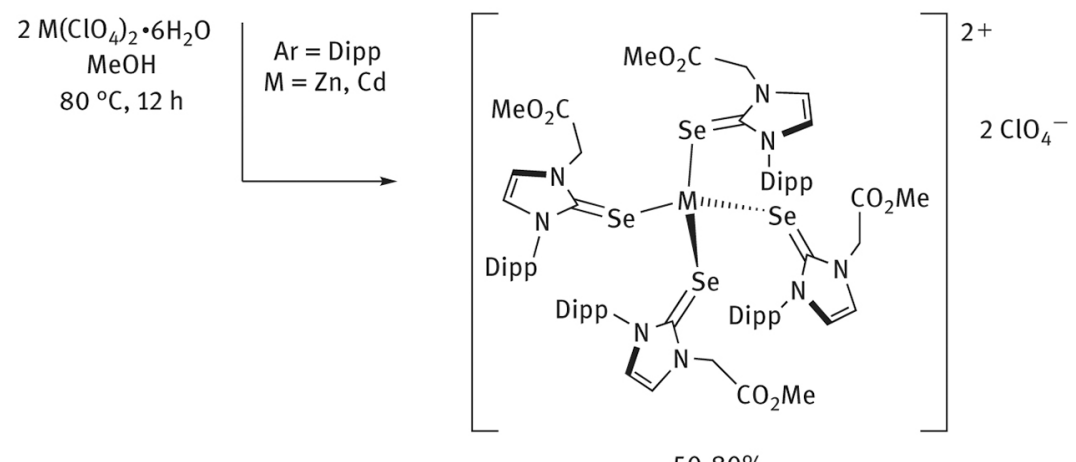

$50-80 \%$ 
A dmise adduct of cadmium(II) hexafluorophosphate - the first homoleptic selenourea-cadmium complex, was reported in 2007 (eq. (23)) [47]. Using mixed aryl/alkyl ester ligands (as in eq. (22)), three unique structural motifs are obtainable when reacted with cadmium salts in methanolic $\mathrm{HCl}$ (eq. (24)) [46]. When the aryl substituents are Mes, a cationic complex with one chloride and three selenourea ligands is obtained in the reaction with cadmium perchlorate and when cadmium nitrate is used, a coordination polymer of the form $\left(\mathrm{LCdCl}_{2}\right)_{x}$ is obtained, with distorted trigonal bipyramidal geometry at cadmium. In the case of 2,6-diisopropylphenyl (Dipp) substituents on the nitrogen centres, a neutral complex featuring two selenourea ligands, one nitrate and one chloride, is observed to form.
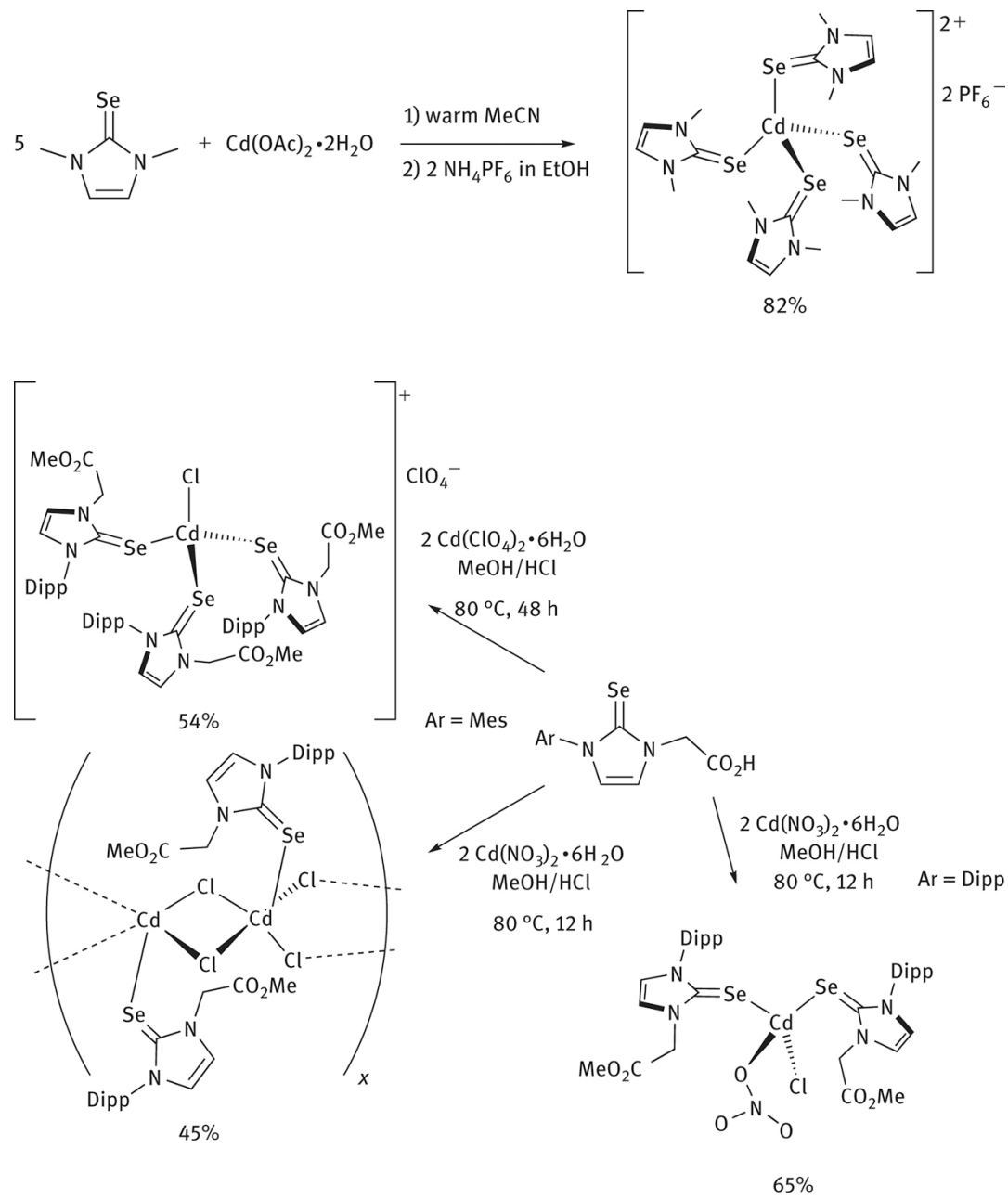

By reacting a benzimidazole selonourea ligand with ether-containing alkyl substituents on nitrogen with cadmium iodide, a bimetallic complex was afforded (eq. (25)) [45]. The metal centres are bridged by two iodide ligands. The analogous reaction with mercury(II) halides affords two bimetallic mercury complexes. The dimeric motif has also arisen from the reaction of $\mathrm{HgCl}_{2}$ with a dicationic diselenide, via cleavage of the Se-Se bond (eq. (25)) [48]. One monomeric mercury complex with distorted tetrahedral geometry has been reported, via a 1:1 reaction of a bidentate selenourea/pyridine ligand with $\mathrm{HgI}_{2}$ (eq. (26)).

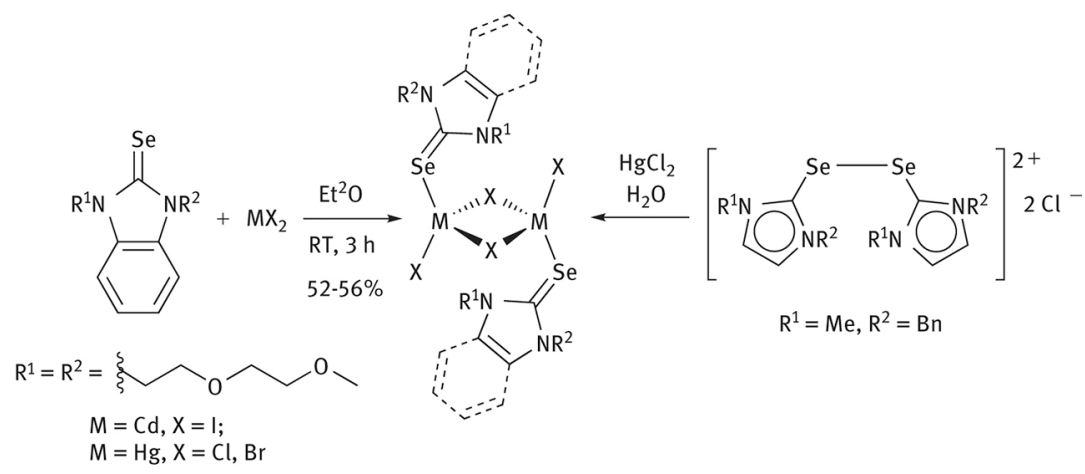




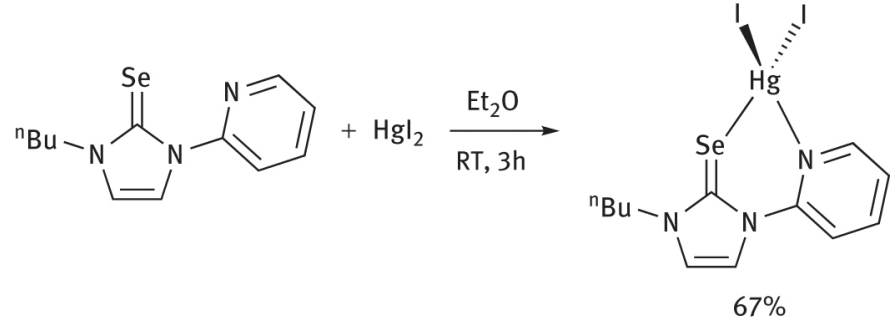

\subsection{Group 11}

At the time of writing, complexes of coinage metals make up over one half of all structurally characterized cyclic HCU-metal adducts, and of these the majority are of copper. The nuclearity and coordination number of the copper complexes vary significantly, depending on the steric and electronic properties of the ligand along with the counterion. Cationic two-coordinate $\mathrm{Cu}^{\mathrm{I}}$ complexes have been obtained by using selenourea ligands with bulky aryl groups installed on the nitrogen centres (eq. (27)) [49]. The metal salts used contain $\mathrm{Cu}^{\mathrm{II}}$, and so the complexation is concomitant with reduction of the metal by some of the chalcogenone. The complexes are centrosymmetric in the solid state, featuring $180^{\circ} \mathrm{Se}-\mathrm{Cu}-\mathrm{Se}$ bond angles, except for one derivative, which crystallized in another space group and is pseudo-centrosymmetric ( $\mathrm{Ar}=\mathrm{Mes}, \mathrm{X}=\mathrm{ClO}_{4} ; 176^{\circ}$ bond angle). In another report, a neutral two-coordination copper(I) complex was obtained by the reaction of a very bulky selenourea with $\mathrm{CuBr}$ in toluene (eq. (28)) [50].
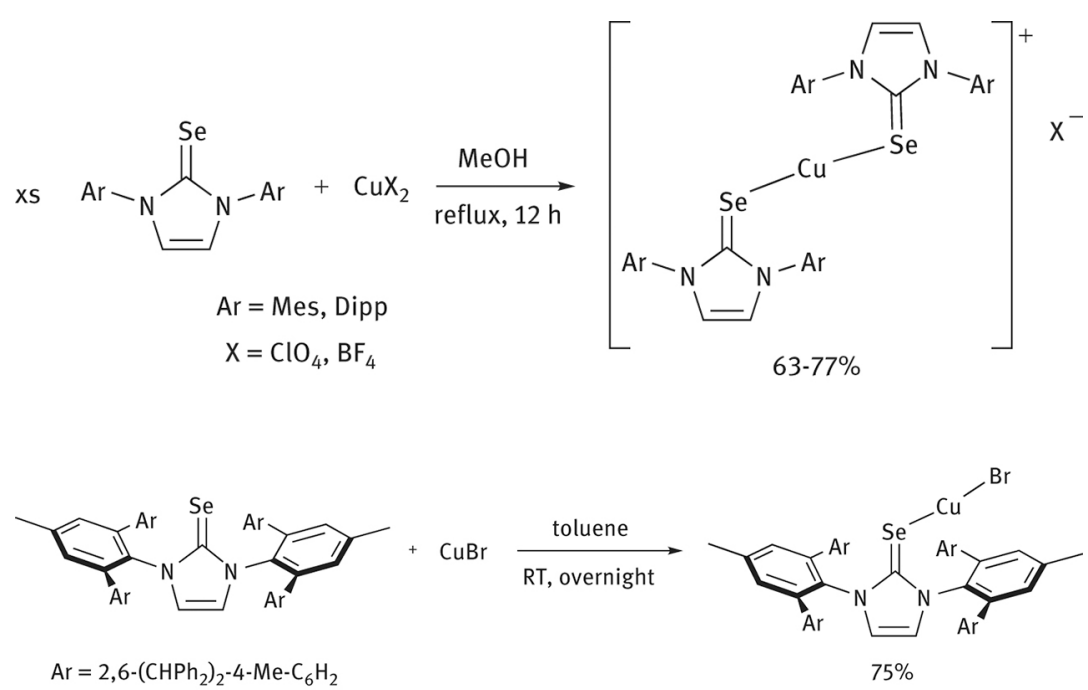

Nearly all of the higher nuclearity/coordination number complexes of $\mathrm{Cu}$ feature the small $N, N^{\prime}-$ dimethylimidazole selone (dmise) ligand or the methylene bridged bis(selone) analogue. An exception is a dimeric copper(I) iodide complex of a benzimidazole selone with $n$-butyl groups on the nitrogen centres (eq. (29)) [45]. The 2:1 reaction of dmise with copper(I) halides (eq. (30)) affords trigonal planar adducts where the two ligands are either syn $(\mathrm{X}=\mathrm{Br}, \mathrm{I})$ or anti $(\mathrm{X}=\mathrm{Cl})$ [51]. The syn conformer exhibits intramolecular $\pi-\pi$ interactions between the imidazole rings. A homoleptic cationic complex is afforded by the reductive coordination of dmise with copper(II) triflate (eq. (31)) [52]. In this reaction, an oxidation product of the HCU, [(dmise $\left.)_{3}\right][\mathrm{OTf}]_{2}$, was also isolated in $15 \%$ yield.
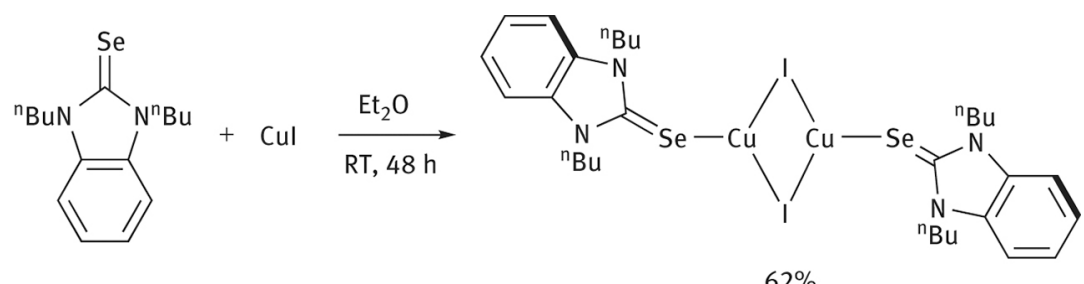


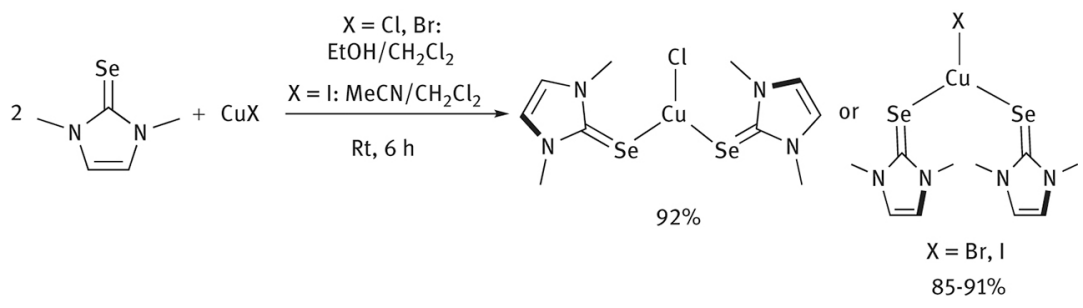

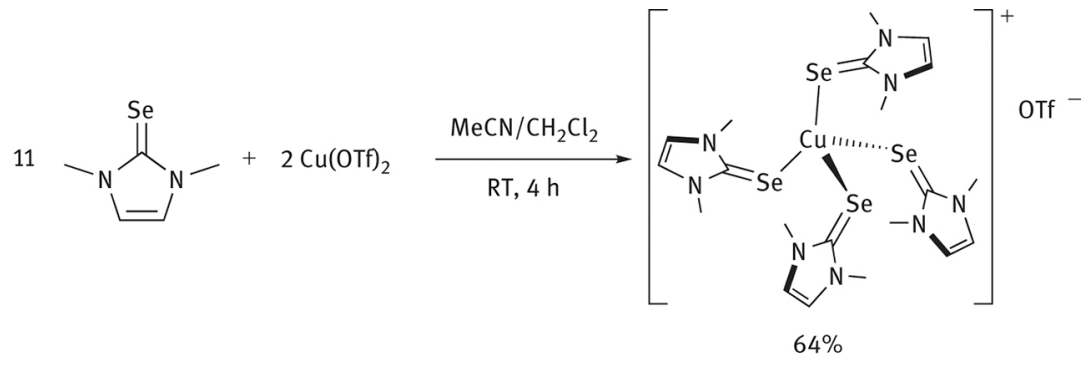

Heteroleptic complexes of dmise and tris(pyrazolyl)methane and tris(pyrazolyl)borate-type ligands are also accessible by reaction of a copper(I) salt with dmise, followed by the tridentate ligand (eq. (32)) [53]. One structure containing a copper(II) centre has been reported. The strategy used to stabilize the +2 oxidation state in the presence of the reducing selenourea ligand was to bind $\mathrm{Cu}^{\mathrm{II}}$ with $\pi$-acidic phenanthroline ligands prior to coordination with dmise (eq. (33)) [54]. The copper(II) centre exhibits a distorted trigonal bipyramidal geometry, with the selenium donor atom in one of the equatorial sites.
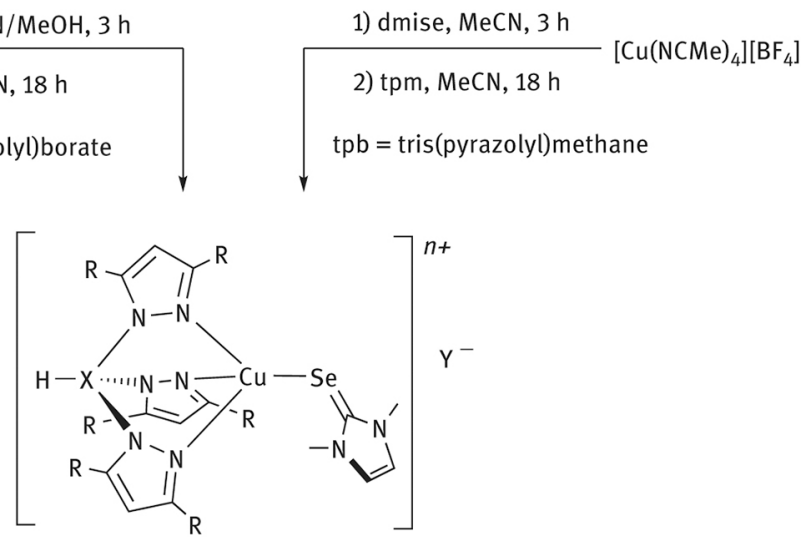

$\mathrm{X}=\mathrm{B}, \mathrm{R}=\mathrm{Me}, \quad n=0$;

$\mathrm{X}=\mathrm{C}, \mathrm{R}=\mathrm{H}, \mathrm{Me}, \quad \mathrm{P} r, n=1, \mathrm{Y}=\mathrm{BF}_{4}$ $59-83 \%$

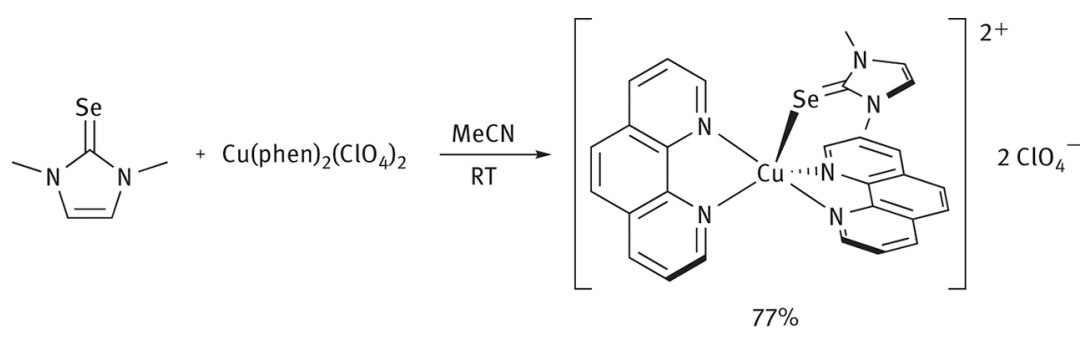

Four dinuclear complexes featuring copper(I) have been synthesized and structurally characterized [55]. The 1:1 reaction of bmise with tetrakis(acetonitrile)copper(I) tetrafluoroborate afforded a 3:2 ligand:metal complex featuring two copper centres, each chelated by one bmise and bridged together by a third ligand (eq. (34)). The central $\mathrm{Cu}_{2} \mathrm{Se}_{2}$ ring is butterfly-shaped. 

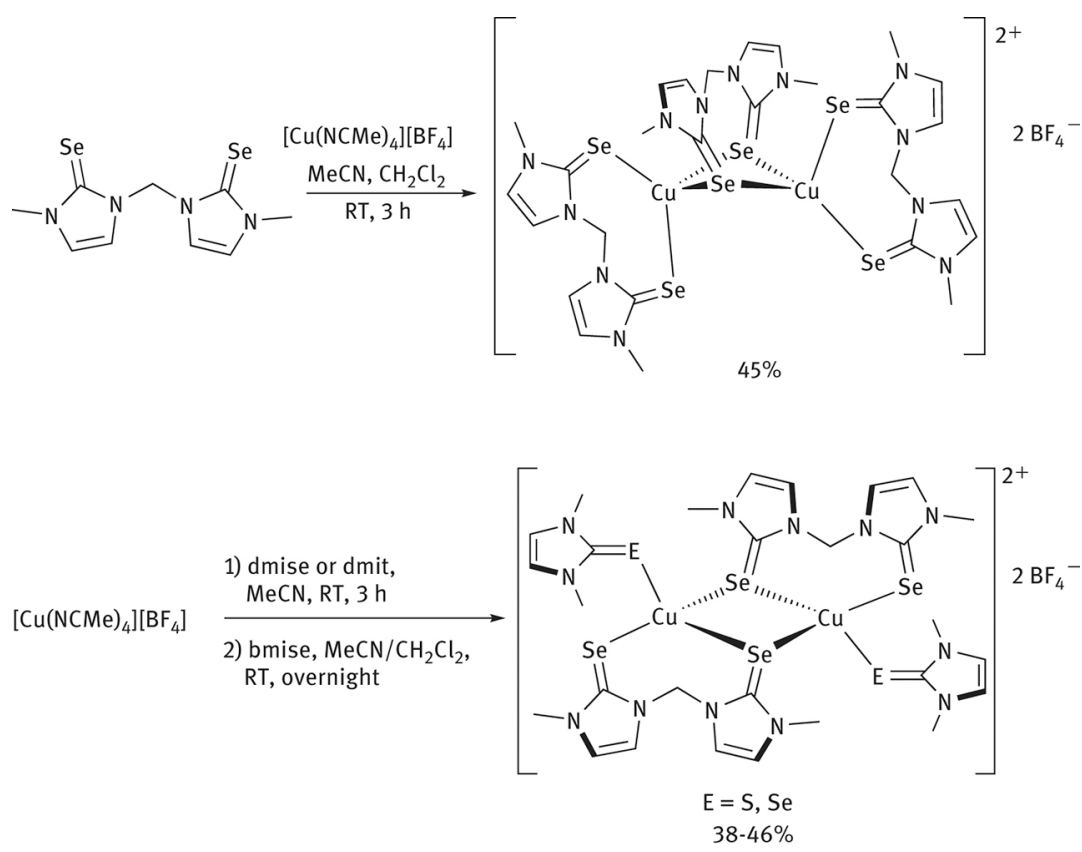

When using a mixture of monodentate and bidentate chalcogenourea ligands in a stepwise fashion (eq. (35)), another bimetallic complex with tetrahedral coordination is formed, but in this case the central $\mathrm{Cu}_{2} \mathrm{Se}_{2}$ ring is planar, with each bridging selenium donor belonging to a different bmise ligand. The other selenium centre on each bidentate ligand is terminal, and one terminal dmise ligand completes the coordination sphere of each metal centre. Using only dmise afforded another bimetallic complex, with both copper centres exhibiting trigonal planar geometry (eq. (36)).

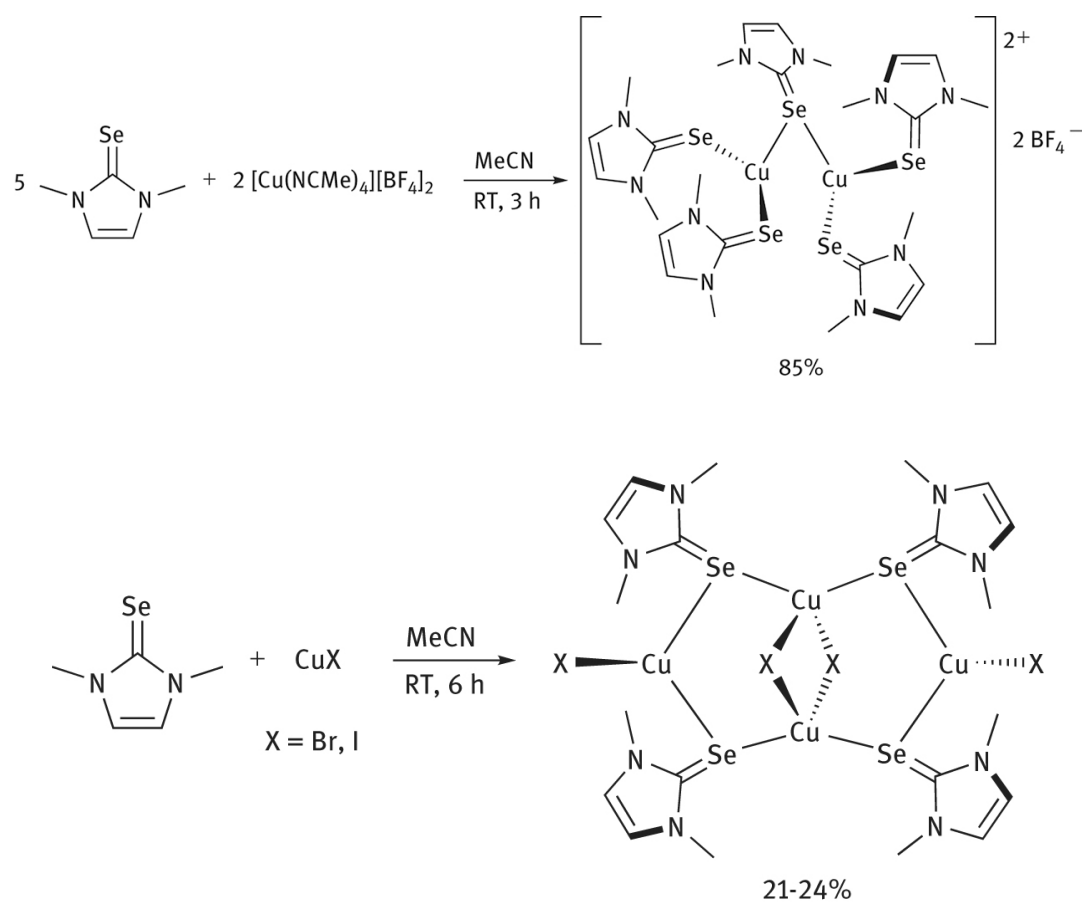

A neutral tetrametallic complex was prepared by the simple 1:1 reaction of copper(I) bromide or iodide with dmise, in acetonitrile (eq. (37)) [51]. The structure is quite distinct from the tetrabismuth complex in eq. (16), which featured octahedral coordination with only halide ligands in bridging positions. The copper(I) centres are tetrahedral and are bridged by both halide and selenourea ligands.

Compared to copper, the cyclic HCU coordination chemistry of the heavier group 11 elements silver and gold is much less thoroughly explored. However, a number of complexes have been structurally characterized in recent years, and these metals have the potential to equal the structural diversity of copper. Heavy group 
11 analogues of the linear copper complexes in eq. (27) can be prepared in an equivalent fashion, using arylsubstituted cyclic selenoureas (eq. (38)). There are, however, noteworthy differences between all the elements. In the case of gold, two structure types were seen: neutral selenourea-gold(I) chloride adducts and cationic bis(selenourea) complexes with a dichloroaurate counterion [56]. For silver, ionic complexes were observed (featuring triflate or dinitritoargentate anions) when a Dipp-substituted ligand was used, but neutral bimetallic complexes with three-coordinate metal centres were seen for the smaller mesityl-substituted analogues [57]. The aggregation mode of gold was surmised to arise from the $\pi$-accepting nature of the selenourea ligands: ionic complexes were observed for more $\pi$-accepting selenoureas (as judged by the ${ }^{77}$ Se chemical shift value) [36-38]. In the case of silver, the bulkier Dipp groups seemed to promote the monometallic ionic form, while the less sterically encumbered Mes group yielded bimetallic complexes.

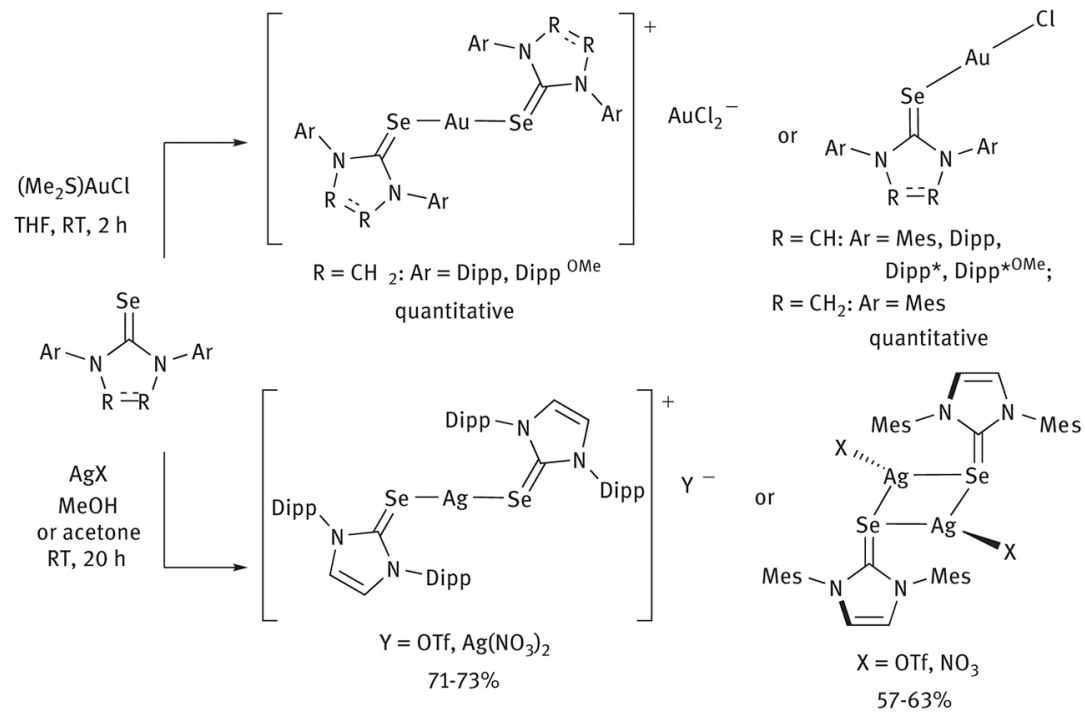

Recrystallization of one bimetallic silver complex $\left(\mathrm{Ar}=\mathrm{Mes}, \mathrm{X}=\mathrm{NO}_{3}\right)$ from hot methanol resulted in the formation of a coordination polymer with three crystallographically distinct silver(I) environments (Figure 6). In this product, the ligand:metal ratio has been altered from 1:1 to 2:3. Two of the silver sites are four coordinate and one is three coordinate, including the weak $\mathrm{Ag} \cdots \mathrm{O}$ contact which links the monomers together.

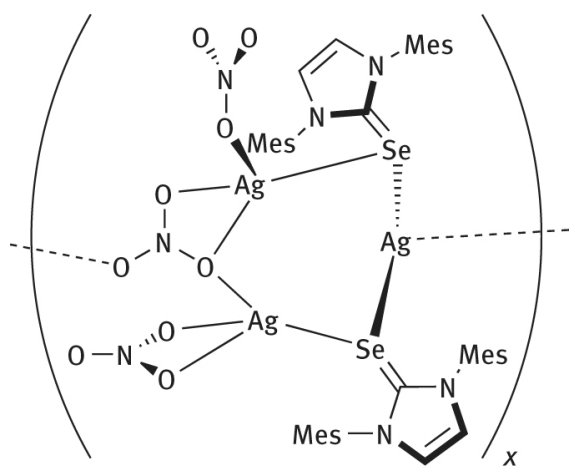

Figure 6: A silver(I) coordination polymer featuring HCU ligands.

The reaction of triphenylphosphine silver(I) triflate and bmise afforded a tetrametallic cluster featuring an $\mathrm{Ag}_{4} \mathrm{Se}_{6}$ diamondoid core, with the four silver centres capped by terminal $\mathrm{PPh}_{3}$ ligands and doubly bridging bmise ligands (eq. (39)) [21]. 


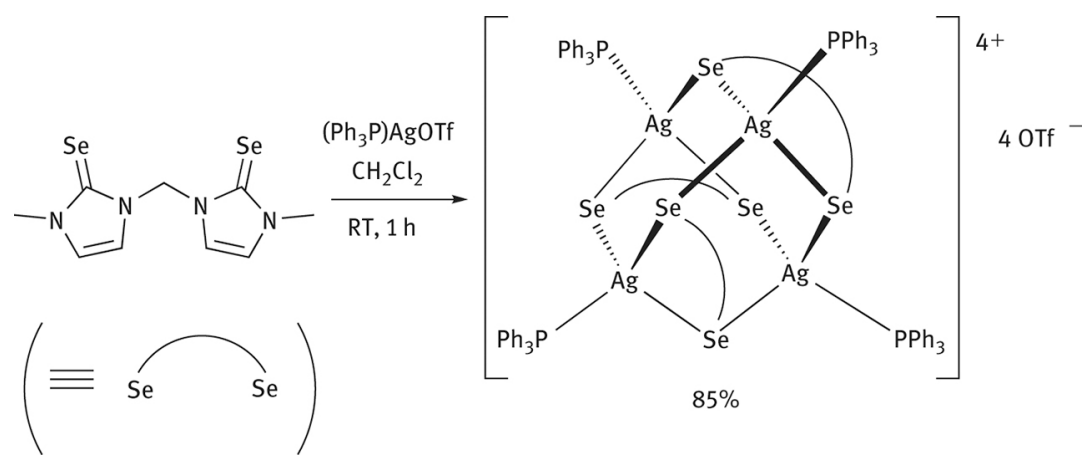

Several more gold(I) and gold(III) coordination complexes have been characterized. Treatment of a (NHC)gold(I) hydroxide complex with a diaryl selenourea and $\mathrm{HNEt}_{3} \mathrm{~F}$ afforded a heteroleptic complex (eq. (40)) [58]. The reaction of tetrachloroauric acid with a multidentate selenourea ligand yielded a mixed-valent salt with a gold(III) cation and a gold(I)-containing anion (eq. (40)) [59]. The use of bis(imidazole selone) ligands in combination with pentafluorophenyl-substituted gold(I) and gold(III) salts resulted in two bimetallic salts in which the metal centres are bridged by the whole ligand (eq. (42)), rather than brought into close proximity, c.f. the copper(I) complexes in Equations 34-35 [21]. As expected, the gold(I) complex features linear coordination, while the gold(III) complex exhibits square-planar metal centres.

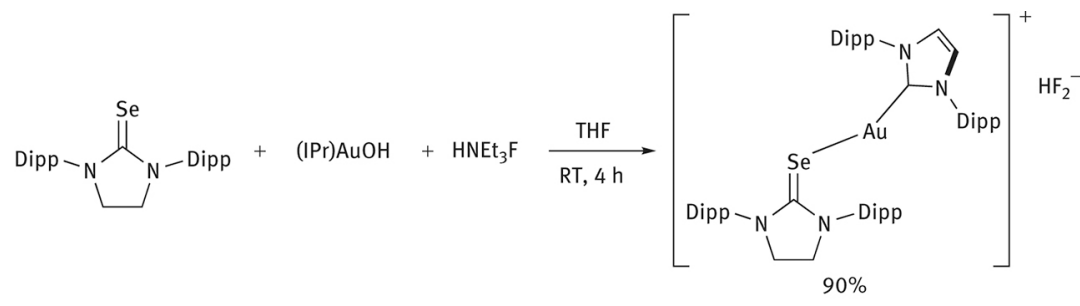
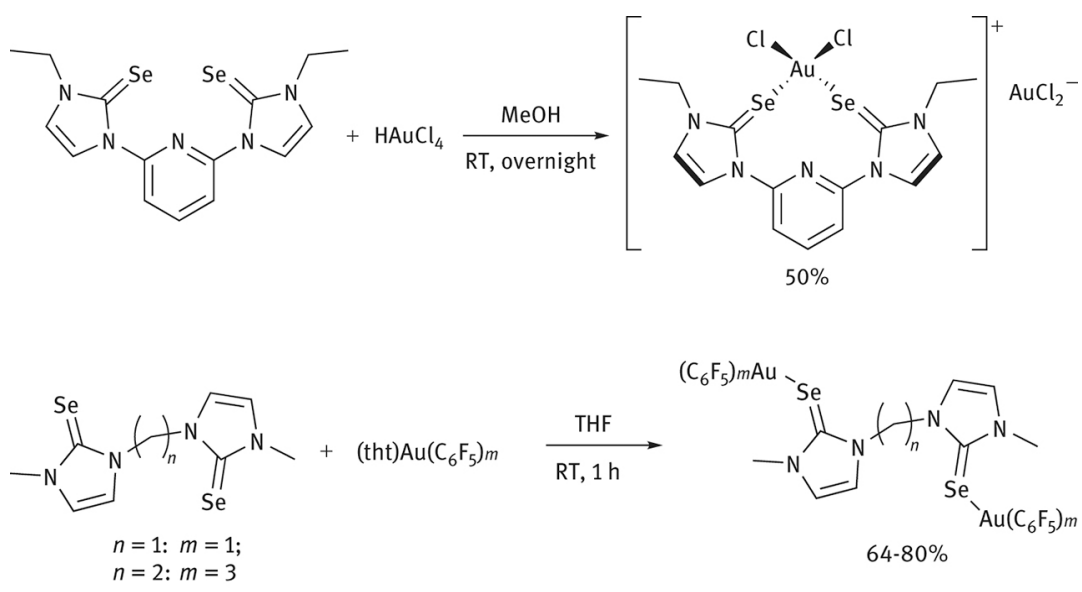

\subsection{Group 10}

Several $\mathrm{M}^{\mathrm{II}}\left(\mathrm{d}^{8}\right)$ complexes of cyclic HCUs have been synthesized and characterized by X-ray diffraction. The lack of $\mathrm{M}^{\mathrm{IV}}$ complexes is to be expected, given the reducing nature of the chalcogenoureas. Two nickel(II) complexes have been reported: one neutral $\mathrm{NiBr}_{2}$ adduct with tetrahedral geometry (eq. (43)) [60] and one cationic, distorted octahedral selenourea adduct featuring a macrocyclic ligand (eq. (44)) [61]. Palladium(II) is also represented by one cationic and one neutral complex. Starting from a potential SeCSe pincer ligand precursor, the reaction with bis(benzonitrile)dichloropalladium(II) under anion exchange conditions afforded a dicationic complex with a square-planar, $\mathrm{PdSe}_{4}$ core (eq. (45)) [22]. The same bis(selenourea) in reaction with a dipalladium complex afforded a neutral, monodechalcogenated product. The low yield and missing selenium atom in the product complex indicate formation of palladium selenide phases as a likely side reaction. 


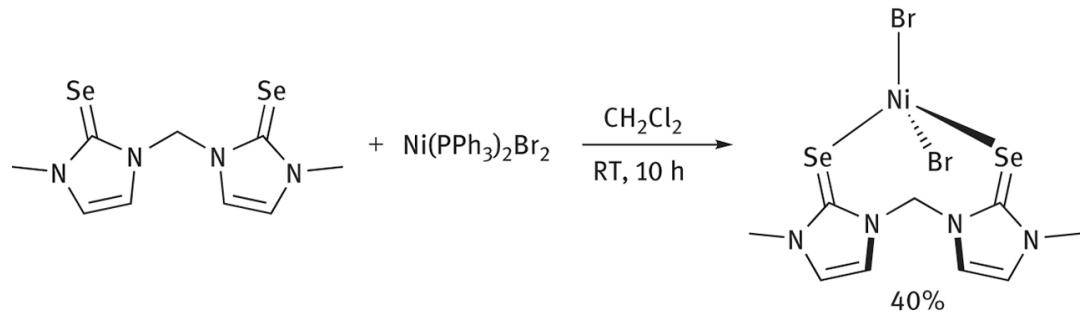
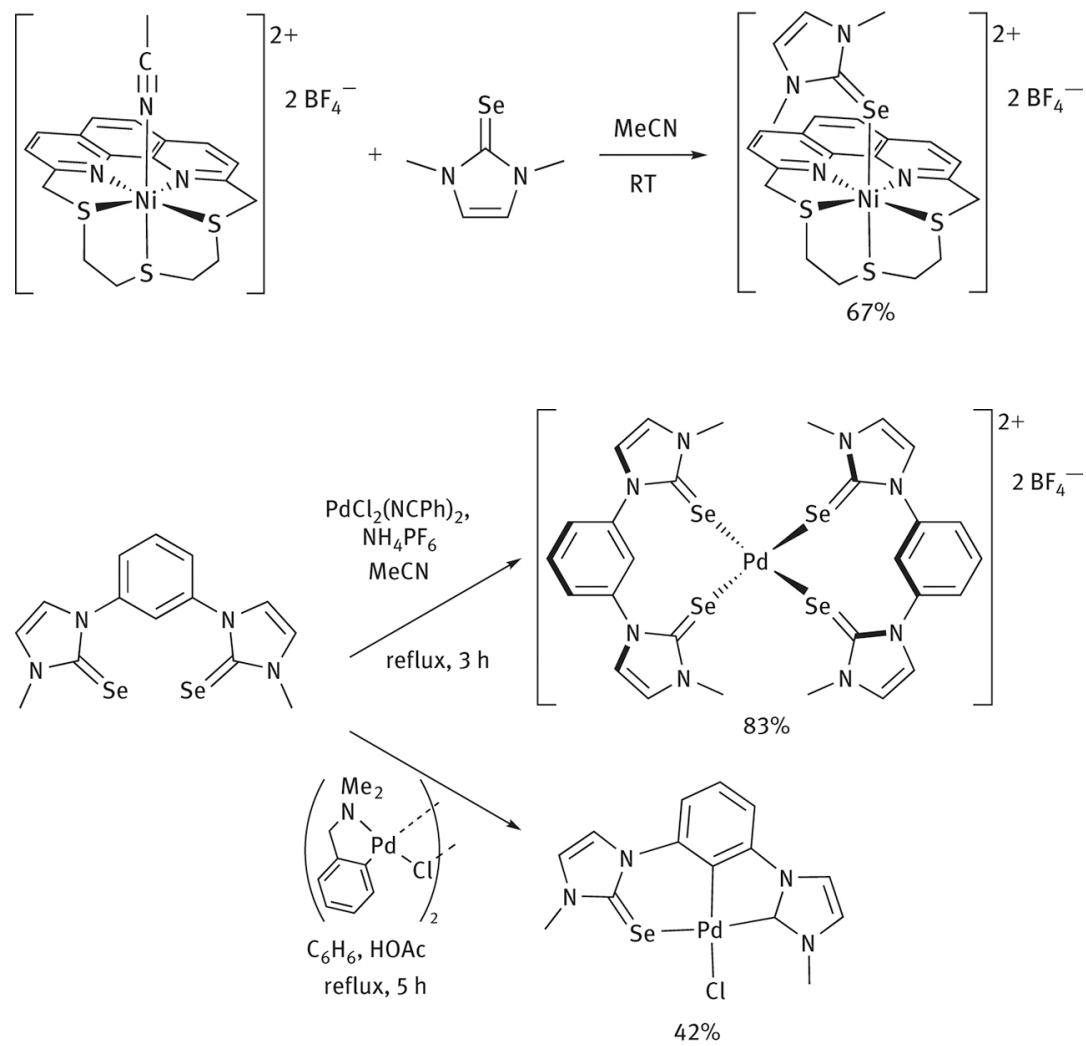

Several dinuclear complexes of palladium, and one of platinum, are also known. A crystal growth experiment featuring an imidazole selenourea and palladium(II) chloride yielded a bimetallic complex featuring bridging selenium atoms in cis orientations (eq. (46)) [62]. Unlike the silver complexes in eq. (38), the central ring is not square but rather a butterfly-shaped motif, with the two cis chloride ligands completing each square-planar palladium(II) metal centre being syn to each other. The imidazole rings are also nearly in the same plane, with the smaller methyl substituents of each ligand oriented towards each other. One platinum and one palladium dimeric complex were obtained by reaction with a aryl-bridged bis(selenourea) ligand (eq. (47)) [63]. When reacted with the $\mathrm{Pd}^{0}$ source $\mathrm{Pd}_{2}(\mathrm{dba})_{3}$, the same ligand yielded an intractable mixture with no detectable oxidative addition across the aryl C-Br bond.<smiles></smiles>

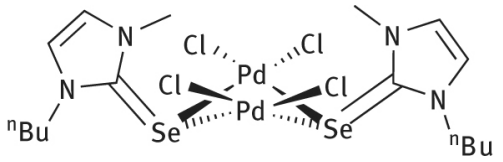




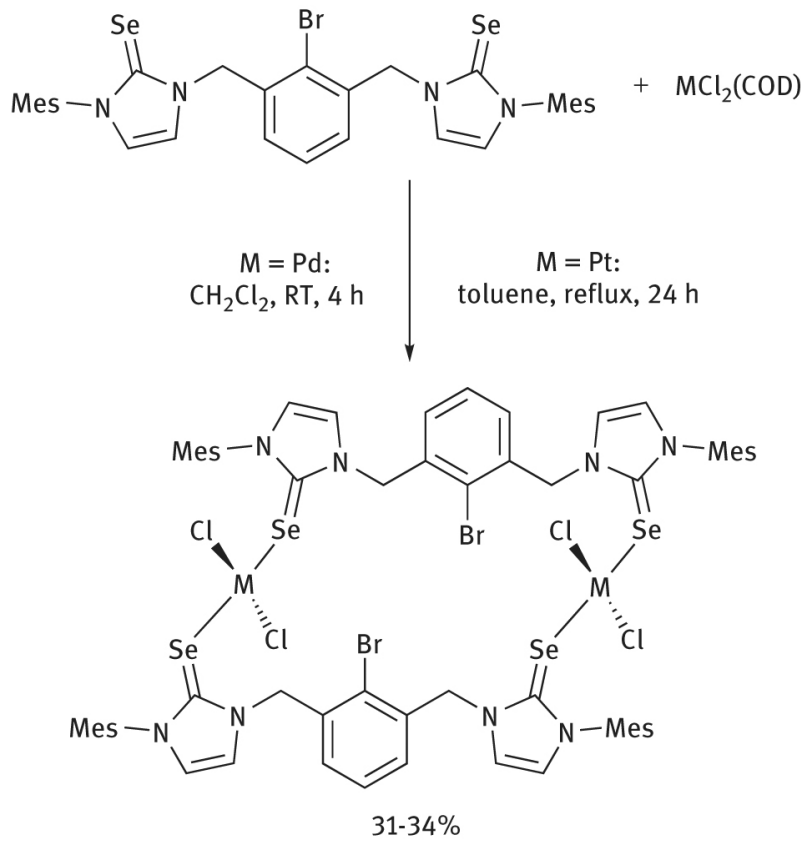

\subsection{Group 9}

Two cobalt complexes have been structurally characterized. A monomeric bis(selenourea) adduct similar to $\mathrm{ZnCl}_{2}$ (dmise) $)_{2}$ (eq. (21)) was prepared by boiling down a methanolic of the ligand and metal salt (eq. (48)) [64]. A coordination polymer of a bis(selenourea) was obtained upon reaction of the ligand with $\mathrm{CoCl}_{2}$ in THF (eq. (49)) [60]. The structure features tetrahedral coordination at cobalt, and the packing reveals a racemic mixture of left- and right-handed helical chains.<smiles>Cn1ccn(C)c1=[Se][Ge](Cl)(Cl)[Se]=c1n(C)ccn1C</smiles>

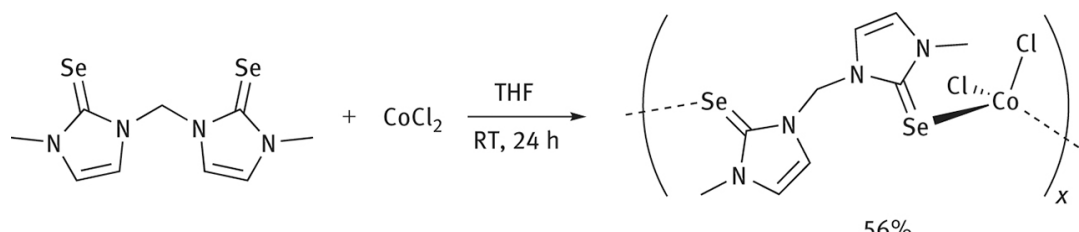

$56 \%$

Complexes of the heavier group 9 elements are all represented as adducts to the $\left[\mathrm{Cp}^{*} \mathrm{MCl}\right]^{+}(\mathrm{M}=\mathrm{Rh}, \mathrm{Ir})$ fragment. Mixing bis(selenourea) ligands with the dimeric $\left[\mathrm{Cp}^{*} \mathrm{MCl}_{2}\right]_{2}$ complexes afforded cationic monomeric complexes featuring the ligands chelating the metal centre (eq. (50)) [65]. The rhodium complex featured a rhodate(III) complex anion, while for iridium the counterion was chloride. Two related $\mathrm{II}^{\mathrm{III}}$ complexes feature a bidentate ligand with one benzimidazole selenourea donor and either a pendant thio- or selenoether substituent on one of the nitrogen atoms (eq. (51)) [66]. 


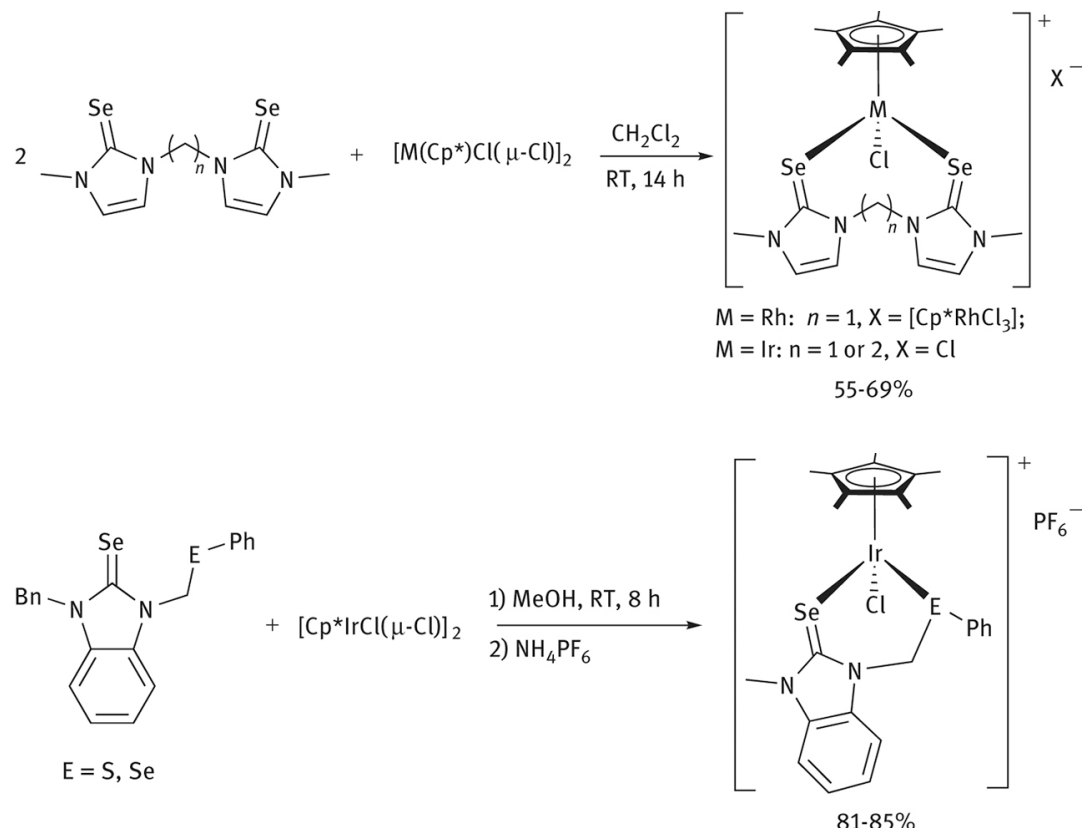

\subsection{Group 8}

Two dmise adducts of iron(II) salts are reported. The simple adduct (dmise) ${ }_{2} \mathrm{FeCl}_{2}$ was prepared by mixing the ligand and iron(II) chloride tetrahydrate in $\mathrm{CH}_{2} \mathrm{Cl}_{2} / \mathrm{HC}(\mathrm{OEt})_{3}$ solvent system (eq. (52)) [67]. Under these conditions, the triethyl orthoformate acts as both a solvent and a water scavenger via its hydrolysis reaction. The same report discloses that the 4:1 reaction of dmise with iron(II) tetrafluoroborate yields a cationic complex similar to the copper(I) complex in eq. (31). Two cationic ruthenium(II) complexes are generated using the same procedure shown in eq. (53) [68].

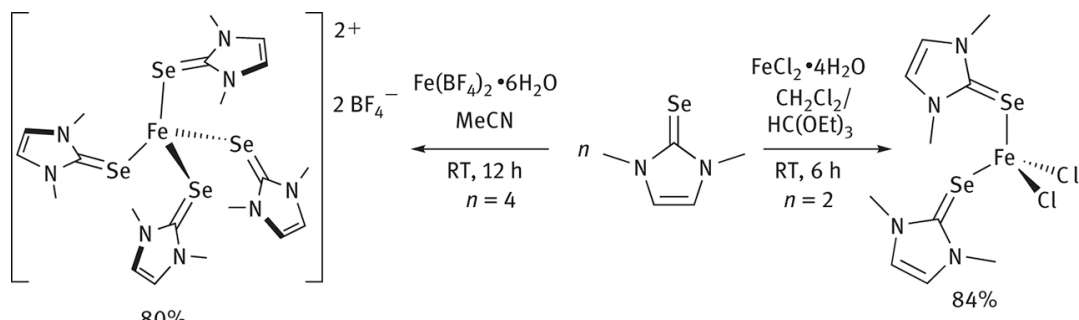

$80 \%$

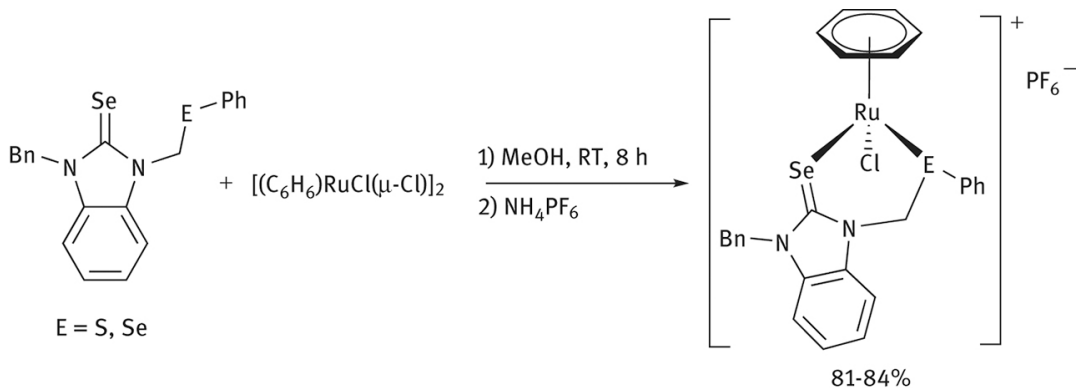

\subsection{Group 6}

The one and only crystal structure of a group 6 complex of a cyclic HCU dates back to the 1980 report of the first well-characterized tellurourea [16]. Treatment of the imidazoline tellurourea with a $\mathrm{Cr}^{0}$ source afforded 
the $1: 1$ adduct of ligand to the $\mathrm{Cr}(\mathrm{CO})_{5}$ fragment (eq. (54)). This is also the only structurally characterized cyclic tellurourea complex. It slowly decomposes at $20^{\circ} \mathrm{C}$ in toluene solution via detelluration.<smiles>CCN1CCN(CC)C1=O</smiles>

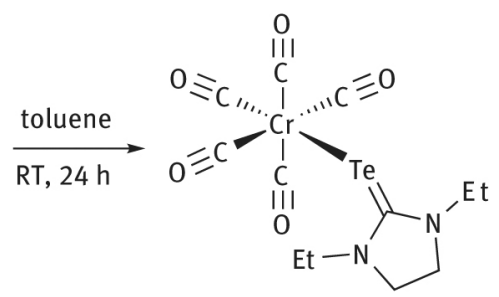

\section{Conclusions and outlook}

Cyclic HCUs featuring selenium and tellurium are accessible by a number of reliable synthetic routes, building upon the well-explored chemistry of NHCs. They can be designed with different heterocyclic cores and organic substituents on nitrogen. The coordination chemistry of HCUs clearly shows a preference for softer metals, particularly late d-block metals. There remain many metals for which HCU complexes are not known. In particular, crystallographic studies of s-block and f-block metal complexes are completely absent at the time of writing. The tellurium derivatives are barely represented in crystallographic studies of coordination chemistry, with only single reported example. This paucity of data is understandable, given the lower solubility of telluroureas compared to selenoureas, and their lower chemical stability.

However, this represents an exciting opportunity for future explorations of these compounds. It is possible the coordination chemistry of both seleno- and telluroureas could be greatly expanded by using multifunctional hybrid ligands (e. g. chelating bidentate or tridentate ligands) featuring strong donors such as phosphines or carbenes, to increase the range of stable metal complexes available. Tellurourea solubility issues could be addressable by installing lipophilic substituents on nitrogen. The lower chemical stability of the $C=T e$ bond may be exploitable in the design of new non-innocent ligands, which may transfer tellurium to chalcophilic metals. For instance, the reaction of 1,3-diisopropylimidazole tellone with a $\mathrm{Mn}^{0}$ precursor was recently shown to yield insertion products in which (MnTe $)_{n}$ clusters formed cubane and dicubane motifs, ligated by the remaining NHC fragment [69]. This type of chemistry has the potential to generate other new metal chalcogenide clusters.

Overall, the chemistry of cyclic HCUs remains very active, with many recent studies elaborating new aspects of the synthetic and structural chemistry of these ligands and their resultant metal complexes. Given this pace, the future looks very promising for the discovery of even more new structure types and modes of reactivity.

\section{Funding}

Financial support from the Natural Sciences and Engineering Research Council (Canada) and the University of Winnipeg is gratefully acknowledged. Prof. Neil Burford is thanked for hosting JSR's sabbatical visit to the University of Victoria in summer 2017, during which a portion of this chapter was written.

\section{Abbreviations}

DBU 1,8-diazabicyclo[5.4.0]undec-7-ene

Mes 2,4,6-trimethylphenyl (mesityl)

Dipp*OMe 2,6-bis(diphenylmethyl)-4-methoxyphenyl

Dipp* 2,6-bis(diphenylmethyl)-4-methylphenyl

Dipp 2,6-diisopropylphenyl

Dipp ${ }^{\text {OMe }}$ 2,6-diisopropyl-4-methoxyphenyl 


\section{Bn benzyl}

Bmise bis( $N$-methylimidazole selone)methane

dba dibenzylideneacetone

HCU heavy chalcogenourea

MW microwave

NHC N-heterocyclic carbene

dmise $N, N^{\prime}$-dimethylimidazole selone

IPr N,N'-bis(2,6-diisopropylphenyl)imidazol-2-ylidene

IMes $N, N^{\prime}$-bis(2,4,6-trimethylphenyl)imidazol-2-ylidene

THF tetrahydrofuran

OTf trifluoromethanesulfonate (triflate)

\section{References}

[1] García-Rodríguez R, Hendricks MP, Cossairt BM, Liu H, Owen JS. Conversion reactions of cadmium chalcogenide nanocrystal precursors. Chem Mater. 2013;25:1233-49.

[2] Campos MP, Hendricks MP, Beecher AN, Walravens W, Swain RA, Cleveland GT, et al. A library of selenourea precursors $\underline{\text { to }} \underline{\text { PbSe }}$ nanocrystals with size distributions near the homogeneous limit. J Am Chem Soc. 2017;139:2296-305.

[3] Lippolis V. The relevant chemistry of imidazoline-2-selone donors with potential biological applications. In: Jain V.K., Priyadarsini K.I., editor(s). Organoselenium compounds in biology and medicine. London, UK: Royal Society of Chemistry, 2017:122-49.

[4] Stadelman BS, Brumaghim JL. Thione- and selone-containing compounds, their late first row transition metal coordination chemistry, and their biological potential. In: Bayse C.A., Brumaghim J.L., editor(s). Biochalcogen chemistry: The biological chemistry of sulfur, selenium, and tellurium. Washington, DC, USA: American Chemical Society, 2013:33-70.

[5] Hussain RA, Badshah A, Shah A. Synthesis and biological applications of selenoureas. Appl Organomet Chem. 2014;28:61-73.

[6] Roy G, Jayaram PN, Mugesh C. Inhibition of lactoperoxidase-catalyzed oxidation by imidazole-based thiones and selones: A mechanistic study. Chem - Asian ]. 2013;8:1910-21.

[7] Kuhn N, Al-Sheikh A. 2, 3-dihydroimidazol-2-ylidenes and their main group element chemistry. Coord Chem Rev. 2005;249:829-57.

[8] Kirmse W. Carbene complexes of nonmetals. Eur] Org Chem. 2005;237-60.

[9] Benhamou L, Chardon E, Lavigne G, Bellemin-Laponnaz S, César V. Synthetic routes to N-heterocyclic carbene precursors. Chem Rev. 2011;111:2705-33.

[10] Arduengo A], Harlow RL, Kline M. A stable crystalline carbene. ] Am Chem Soc. 1991;113:361-3.

[11] Kuhn N, Kratz T. Synthesis of imidazol-2-ylidenes by reduction of imidazole-2(3H)-thiones. Synthesis. 1993;561-2.

[12] Kuhn N, Henkel G, Kratz T. Beiträge zur chemie des Imidazols, III. 2-telluroimidazoline — Stabile tellurocarbonyl-verbindungen. Chem Ber. 1993;126:2047-9.

[13] Arduengo A], Davidson F, Dias HV, Goerlich JR, Khasnis D, Marshall W], et al. An air stable carbene and mixed carbene "dimers". ] Am Chem Soc. 1997;119:12742-9.

[14] Kuhn N, Henkel C, Kratz T. 2-selenoimidazoline/2-selenoimidazolines. Z Für Naturforschung B. 1993;48:973-7.

[15] Schönberg A, Singer E, Stephan W. C=C-doppelbindungen mit extremer reaktivität, II. 1,3-diphenyl-2-imidazolidinselenon aus 1,1' $3,3^{\prime}$ tetraphenyl- $\Delta 2,2^{\prime}$-biimidazolidin und selen. Chem Ber. 1983;116:2068-73.

[16] Lappert MF, Martin TR, McLaughlin CM. Telluroureas and derived transition metal complexes: The crystal and molecular structure of $\left[\mathrm{Cr}(\mathrm{CO}) 5\left\{\mathrm{TeCN}(\mathrm{Et}) \mathrm{CH}_{2} \mathrm{CH}_{2} \mathrm{NEt}\right\}\right]$. ] Chem Soc Chem Commun. 1980;635-7.

[17] Ansell GB, Forkey DM, Moore DW. The molecular structure of 1,3-dimethyl-2(3H)-imidazolethione (C5H8N2S). J Chem Soc Chem Commun 1970 56b-7.

[18] Thompson DP, Boudjouk P. A convenient synthesis of alkali metal selenides and diselenides in tetrahydrofuran and the reactivity differences exhibited by these salts toward organic bromides. Effect of ultrasound. J Org Chem. 1988;53:2109-12.

[19] Bigoli F, Pellinghelli MA, Deplano P, Devillanova FA, Lippolis V, Mercuri ML, et al. Reaction of imidazole-2-selone derivatives with diiodine: Synthesis, structural and spectroscopic characterization of the adduct 1,1-bis(3-methyl-4-imidazoline-2-selone)methane bis(diiodine) and of the first examples of I-Se-I hypervalent selenium compounds: 1,3-dimethyl-4-imidazolin-2-ylium diiodo selenanide and 1,2-bis(3-methyl-4-imidazolin-2-ylium diiodo selenanide)ethane bis(dichloromethane). Cazzetta Chim Ital. 1993;124:445-54.

[20] Bhabak KP, Satheeshkumar K, Jayavelu S, Mugesh C. Inhibition of peroxynitrite- and peroxidase-mediated proteintyrosine nitration by imidazole-based thiourea and selenourea derivatives. Org Biomol Chem. 2011;9:7343-50.

[21] Aroz MT, Gimeno MC, Kulcsar M, Laguna A, Lippolis V. Group 11 complexes with imidazoline-2-thione or selone derivatives. Eur] Inorg Chem. 2011;2884-94.

[22] Chavale N, Manjare ST, Singh HB, Butcher R]. Bis(chalcogenones) as pincer ligands: isolation and heck activity of the selone-ligated unsymmetrical C,C,Se-Pd pincer complex. Dalton Trans. 2015;44:11893-900.

[23] Zhou Y, Denk MK. Synthesis and reactivity of subvalent compounds. Part 13: Reaction of triethyl orthoformate with amines and selenium—A convenient one-step three-component synthesis for selenoureas. Tetrahedron Lett. 2003;44:1295-9. 
[24] Williams D], Fawcett-Brown MR, Raye RR, VanDerveer D, Pang YT, Jones RL, et al. Synthesis, characterization, and X-ray crystallographic structure of 1,3-dimethyl-2(3H)-imidazoleselone. Heteroat Chem. 1993;4:409-14.

[25] Banerjee M, Karri R, Rawat KS, Muthuvel K, Pathak B, Roy G. Chemical detoxification of organomercurials. Angew Chem Int Ed. 2015;54:9323-7.

[26] Roy G, Das D, Mugesh C. Bioinorganic chemistry aspects of the inhibition of thyroid hormone biosynthesis by anti-hyperthyroid drugs. Inorganica Chim Acta. 2007;360:303-16.

[27] Bhabak KP, Mugesh G. Antithyroid drugs and their analogues protect against peroxynitrite-mediated protein tyrosine nitration-A mechanistic study. Chem - Eur ]. 2010;16:1175-85.

[28] Arca M, Demartin F, Devillanova FA, Isaia F, Lelj F, Lippolis V, et al. An experimental and theoretical approach to the study of the properties of parabanic acid and related compounds: Synthesis and crystal structure of diethylimidazolidine-2-selone-4,5-dione. Can ] Chem. 2000;78:1147-57.

[29] Klayman DL, Shine R]. Synthesis of selenoureas and selenothiocarbamic esters from thioureas. ] Org Chem. 1969;34:3549-51.

[30] Nakayama ], Kitahara T, Sugihara Y, Sakamoto A, Ishii A. Isolable, stable diselenocarboxylate and selenothiocarboxylate salts: Syntheses, structures, and reactivities of 2-(1,3-dimethylimidazolidinio)diselenocarboxylate and 2-(1,3dimethylimidazolidinio)selenothiocarboxylate. J Am Chem Soc. 2000;122:9120-6.

[31] Segi M, Maeda H, Sakata K, Takashima M, Honda M, Watanabe T. Synthesis of selenohydantoins from isoselenocyanates and $\underline{\alpha-a m i n o}$ acids. Heterocycles. 2010;82:1709-17.

[32] Manjare ST, Sharma S, Singh HB, Butcher R]. Facile synthesis of benzimidazolin-2-chalcogenones: Nature of the carbon-chalcogen bond. J Organomet Chem. 2012;717:61-74.

[33] Rong Y, Al-Harbi A, Kriegel B, Parkin C. Structural characterization of 2-imidazolones: Comparison with their heavier chalcogen counterparts. Inorg Chem. 2013;52:7172-82.

[34] Cordero B, Cómez V, Platero-Prats AE, Réves M, Echeverría ], Cremades E, et al. Covalent radii revisited. Dalton Trans. 2008;2832-8.

[35] Aygun M, Çetinkaya E, Cök Y, Kendi E, Çetinkaya B. Synthesis and crystal structure of hexahydrobis[(1,3-p-dimethylaminobenzyl)-1,3diazepine]-2-selenone, $\mathrm{C}_{23} \mathrm{H} 32 \mathrm{~N} 4 \mathrm{Se}$. Anal Sci. 2003;19:1093-4.

[36] Vummaleti SV, Nelson D], Poater A, Cómez-Suárez A, Cordes DB, Slawin AMZ, et al. What can NMR spectroscopy of selenoureas and phosphinidenes teach us about the $\pi$-accepting abilities of $\mathrm{N}$-heterocyclic carbenes?. Chem Sci. 2015;6:1895-904.

[37] Liske A, Verlinden K, Buhl H, Schaper K, Ganter C. Determining the $\pi$-acceptor properties of N-heterocyclic carbenes by measuring the 77Se NMR chemical shifts of their selenium adducts. Organometallics. 2013;32:5269-72.

[38] Verlinden K, Buhl H, Frank W, Ganter C. Determining the ligand properties of N-heterocyclic carbenes from 77Se NMR parameters. Eur ] Inorg Chem. 2015;2416-25.

[39] Back O, Henry-Ellinger M, Martin CD, Martin D, Bertrand G. 31P NMR chemical shifts of carbene-phosphinidene adducts as an indicator of the $\pi$-accepting properties of carbenes. Angew Chem Int Ed. 2016;52:2939-43.

[40] Arca M, Aroz T, Concepción Cimeno M, Kulcsar M, Laguna A, Lasanta T, et al. Homopolynuclear Tll and heteropolynuclear Aul-TII complexes with organodiselone ligands: Activation of luminescence by intermetallic interactions. Eur ] Inorg Chem. 2011;2288-97.

[41] Manjare ST, Yadav S, Singh HB, Butcher R]. Redox reaction between main-group elements (Te, Sn, Bi) and N-heterocyclic-carbenederived selenium halides: A facile method for the preparation of monomeric halides. Eur ] Inorg Chem. 2013;5344-57.

[42] Srinivas K, Suresh P, Babu CN, Sathyanarayana A, Prabusankar G. Heavier chalcogenone complexes of bismuth(III)trihalides: Potential catalysts for acylative cleavage of cyclic ethers. RSC Adv. 2015;5:15579-90.

[43] Burford N, Phillips AD, Spinney HA, Robertson KN, Cameron TS, McDonald R. Chalcogeno-urea ligands on a phosphadiazonium Lewis acceptor: A new synthetic approach to $\mathrm{Ch}-\mathrm{P}$ bonds $(\mathrm{Ch}=\mathrm{O}$, S, Se). Inorg Chem. 2003;42:4949-54.

[44] Williams D], White KM, VanDerveer D, Wilkinson AP. Dichlorobis[1,3-dimethyl-2(3H)-imidazoleselone]zinc(II): A potential zinc selenide synthon. Inorg Chem Commun. 2002;5:124-6.

[45] Yadav S, Singh HB, Butcher R]. Synthesis and reactivity of selones and dihaloselones: Complexation of selones with d8-and d10-metal ions. Eur] Inorg Chem. 2017;2968-79.

[46] Babu CN, Srinivas K, Prabusankar G. Facile access to zinc and cadmium selones: Highly active catalysts for barbier reactions in aqueous media. Dalton Trans. 2016;45:6456-65.

[47] Williams D], McKinney B], Baker B, Gwaltney KP, VanDerveer D. The preparation, characterization and X-ray structural analysis of tetrakis[1,3-dimethyl-2(3H)-imidazoleselone]cadmium(II) hexafluorophosphate. ] Chem Crystallogr. 2007;37:691-4.

[48] Choi ], Park SY, Yang HY, Kim H], Ihm K, Nam JH, et al. Submicro-polymer particles bearing imidazoline-2-selenone: Dual mode adsorbents with color-sensing for halogens and mercury ions. Polym Chem. 2011;2:2512-7.

[49] Srinivas K, Babu CN, Prabusankar G. Linear Cu(I) chalcogenones: synthesis and application in borylation of unsymmetrical alkynes. Dalton Trans. 2015;44:15636-44.

[50] Parvin N, Pal S, Khan S, Das S, Pati SK, Roesky HW. Unique approach to copper(I) silylene chalcogenone complexes. Inorg Chem. 2017;56:1706-12.

[51] Kimani MM, Bayse CA, Brumaghim ]L. Synthesis, characterization, and DFT studies of thione and selone Cu(I) complexes with variable coordination geometries. Dalton Trans. 2011;40:3711-23.

[52] Kimani MM, Wang HC, Brumaghim ]L. Investigating the copper coordination, electrochemistry, and Cu(II) reduction kinetics of biologically relevant selone and thione compounds. Dalton Trans. 2012;41:5248-59.

[53] Kimani MM, Brumaghim ]L, VanDerveer D. Probing the antioxidant action of selenium and sulfur using $\mathrm{Cu}(\mathrm{I})$-chalcogenone tris(pyrazolyl)methane and -borate complexes. Inorg Chem. 2010;49:9200-11.

[54] Blake A], Lippolis V, Pivetta T, Verani C. (1,3-Dimethylimidazolidine-2-selone-kSe)bis(1,10-phenanthroline-k2N, $\left.\mathrm{N}^{\prime}\right) \operatorname{copper(II)}$ bis(perchlorate) and bis(2,2'-bipyridyl-k2N,N')(imidazolidine-2-thione-kS)copper(II) bis(perchlorate). Acta Crystallogr C. 2007;63:m364-7.

[55] Kimani MM, Watts D, Graham LA, Rabinovich D, Yap CP, Brumaghim JL. Dinuclear copper(I) complexes with N-heterocyclic thione and selone ligands: synthesis, characterization, and electrochemical studies. Dalton Trans. 2015;44:16313-24. 
[56] Nelson D], Nahra F, Patrick SR, Cordes DB, Slawin AM, Nolan SP. Exploring the coordination of cyclic selenoureas to gold(I). Organometallics. 2014;33:3640-5.

[57] Perras ]H, Mezibroski SM, Wiebe MA, Ritch ]S. Diverse silver(I) coordination chemistry with cyclic selenourea ligands. Dalton Trans. 2018;47:1471-8.

[58] Nahra F, Patrick SR, Bello D, Brill M, Obled A, Cordes DB, et al. Hydrofluorination of alkynes catalysed by gold bifluorides. ChemCatChem. 2015;7:240-4.

[59] Zhang H-N, Jia W-C, Xu Q-T, ]i C-C. Synthesis, characterization and catalytic activity of gold complexes with pyridine-based selone ligands. Inorg Chim Acta. 2016;450:315-20.

[60] ]ia W-G, Huang Y-B, Lin Y-], Wang G-L, Jin G-X. Nickel complexes and cobalt coordination polymers with organochalcogen (S, Se) ligands bearing an N-methylimidazole moiety: Syntheses, structures, and properties. Eur ] Inorg Chem. 2008;4063-73.

[61] Blake A], Casabò ], Devillanova FA, Esriche L, Garau A, Isaia F, et al. Mixed aza-thia crowns containing the 1,10-phenanthroline sub-unit. Substitution reactions in $[\mathrm{NiL}(\mathrm{MeCN})][B F 4] 2\{\mathrm{~L}=2,5,8$-trithia[9](2,9)-1,10-phenanthrolinophane $\}$. ] Chem Soc Dalton Trans. 1999;108592.

[62] Wang C, Tong Y, Huang Y, Zhang H, Yang Y. Selone behavior towards palladium(II) extraction with hydrophobic ionic liquids and mechanism studies. RSC Adv. 2015;5:63087-94.

[63] Rani V, Singh HB, Butcher R]. Bis(selone) complexes of palladium(II), platinum(II), and gold(III): Synthesis and structural studies. Eur ] Inorg Chem. 2017;3720-8.

[64] Williams D], Jones TA, Rice ED, Davis K], Ritchie ]A, Pennington WT, et al. Dichlorobis[1,3-dimethylimidazole-2(3H)selone-Se]cobalt(II). Acta Crystallogr C. 1997;53:837-8.

[65] ]ia W-C, Huang Y-B, Lin Y-], Jin G-X. Syntheses and structures of half-sandwich iridium(III) and rhodium(III) complexes with organochalcogen (S, Se) ligands bearing N-methylimidazole and their use as catalysts for norbornene polymerization. Dalton Trans. 2008;5612-20.

[66] Sharma AK, Joshi H, Bhaskar R, Singh AK. Complexes of ( $\left.\eta 5-C p^{*}\right) \operatorname{Ir}(I I I)$ with 1-benzyl-3-phenylthio/selenomethyl-1,3dihydrobenzoimidazole-2-thione/selenone: Catalyst for oxidation and 1,2-substituted benzimidazole synthesis. Dalton Trans. 2017;46:2228-37.

[67] Stadelman BS, Kimani MM, Bayse CA, McMillen CD, Brumaghim JL. Synthesis, characterization, DFT calculations, and electrochemical comparison of novel iron(II) complexes with thione and selone ligands. Dalton Trans. 2016;45:4697-711.

[68] Sharma AK, Joshi H, Sharma KN, Cupta PL, Singh AK. 2-Propanol vs glycerol as hydrogen source in catalytic activation of transfer hydrogenation with ( $\eta 6$-benzene)ruthenium(II) complexes of unsymmetrical bidentate chalcogen ligands. Organometallics. 2014;33:3629-39.

[69] Choi B, Paley DW, Siegrist T, Steigerwald ML, Roy X. Ligand control of manganese telluride molecular cluster core nuclearity. Inorg Chem. 2015;54:8348-55.

[70] Engl PS, Santiago CB, Gordon CP, Liao W-C, Fedorov A, Copéret C, et al. Exploiting and understanding the selectivity of Ru-N-heterocyclic carbene metathesis catalysts for the ethenolysis of cyclic olefins to $\alpha, \omega$-dienes. J Am Chem Soc. 2017;139:13117-25.

[71] Wonner P, Vogel L, Düser M, Comes L, Kniep F, Mallick B, et al. Carbon-halogen bond activation by selenium-based chalcogen bonding. Angew Chem Int Ed. 2017;56:12009-12.

[72] Rodríguez H, Gurau G, Holbrey JD, Rogers RD. Reaction of elemental chalcogens with imidazolium acetates to yield imidazole-2chalcogenones: direct evidence for ionic liquids as proto-carbenes. Chem Commun. 2011;47:3222-4.

[73] Kuhn N, Fawzi R, Kratz T, Steimann M, Henkel G. Heterocyclen Als liganden Xxii. 2-chalkogenoimidazoline Als liganden in pentacarbonylmetall-komplexen. Phosphorus Sulfur Silicon Relat Elem. 1996;108:107-19.

[74] Liu L, Zhu D, Cao LL, Stephan DW. N-heterocyclic carbene stabilized parent sulfenyl, selenenyl, and tellurenyl cations $(\mathrm{XH}+, \mathrm{X}=\mathrm{S}, \mathrm{Se}, \mathrm{Te})$. Dalton Trans. 2017;46:3095-9. 